
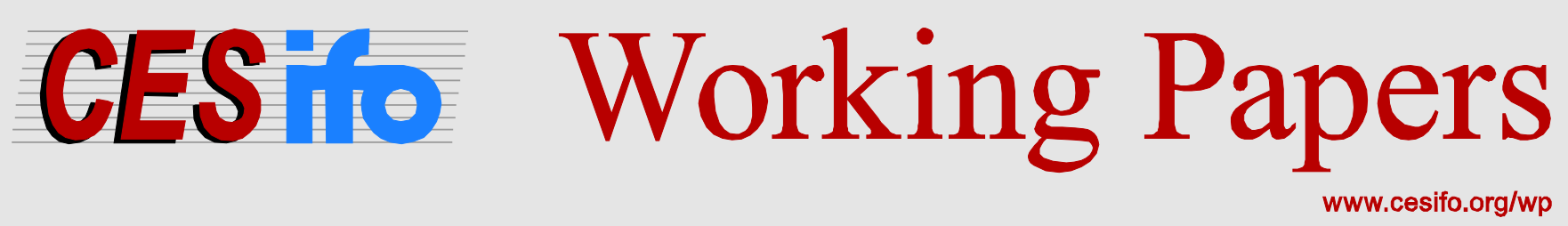

\title{
Corporate Taxation and Financial Strategies Under Asymmetric Information
}

\author{
Francesco Cohen \\ Alessandro Fedele \\ Paolo M. Panteghini
}

\section{CESIFO WORKING PAPER NO. 4772 \\ CATEgory 1: PubliC FinANCE \\ APRIL 2014}

Presented at CESifo Area Conference on Public Sector Economics, April 2013

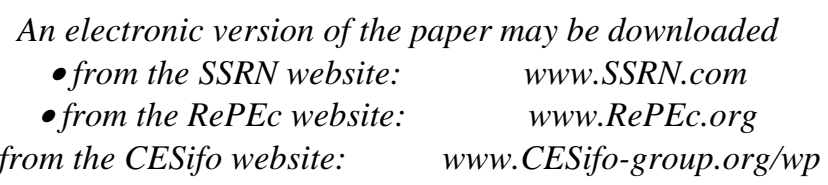




\title{
Corporate Taxation and Financial Strategies Under Asymmetric Information
}

\begin{abstract}
In this article we study the corporate tax effects on credit market equilibria. In particular, we develop a model that accounts for five pieces of evidence: i) the existence of a tax incentive to borrow, ii) the negative relationship between leverage and profitability, iii) the existence of asymmetric information in credit markets, iv) the screening activity of lenders and v) the business cycle effects on the spread between the high-yield and the investment-grade interest rates on corporate loans. Assuming the existence of two types of firms, we show that either a separating or a pooling credit market equilibrium can arise. More importantly, the equilibrium is crucially affected by corporate taxation. Given these results, we also provide a welfare analysis and discuss corporate tax policy implications.
\end{abstract}

JEL-Code: H200, D820.

Keywords: capital structure, corporate taxation, asymmetric information.

Francesco Cohen

Department of Economics \& Management

University of Brescia / Italy

cohen@eco.unibs.it
Alessandro Fedele

School of Economics \& Management

Free University of Bolzano (Bozen) / Italy

alessandro.fedele@unibz.it

Paolo M. Panteghini

Department of Economics \& Management

University of Brescia / Italy

panteghi@eco.unibs.it

April 15, 2014

We thank Dirk Schindler and seminar audience at "11th Journées Louis-André Gérard-Varet” (Marseille, 2012), "XXIV SIEP Conference on Economia informale, evasione fiscale e corruzione" (Pavia, 2012), "CESifo Area Conference on Public Sector Economics" (Muenchen, 2013), "69th Annual Congress of the IIPF” (Taormina, 2013), "11th Annual Meeting of the GLEA” (Bolzano, 2013) for useful comments. The usual caveat applies. 


\section{Introduction}

The deductibility of interest payments ensures a tax benefit to borrowing firms. Therefore, a fair amount of research has found evidence that debt usage is positively affected by corporate tax rates, as argued by Graham (2003). In other words, these results support the idea that companies can trade-off the tax benefits of debt finance with the expected costs of default, therefore obtaining an optimal capital structure. ${ }^{1}$

As stressed by Gordon (2010), however, information asymmetries can explain a corporation's financial choices. In particular, Akerlof's (1970) well-known lemon problem well fits with capital markets. As pointed out by Myers and Majluf (1984), when corporations seek outside finance, investors learn that the firm needs funds. For this reason, they state that firms with less pressing needs for cash (those who are doing well) will forego outside finance, even at the cost of foregoing some good investment projects. Only the weaker firms borrow. ${ }^{2}$ This fact is supported by robust evidence, showing that the use of debt declines when profitability rises. ${ }^{3}$ This led Myers (1993) to state that taxation is irrelevant in terms of financial choices. Subsequently he added that it is "of third-order importance" (Myers et al., 1998).

This lively debate demonstrates that there is much to learn about the possible interactions between taxation and corporate finance. In our view, this can be done by investigating both sides of financial markets. It is worth noting that the above-mentioned literature mainly focuses on the demand side of capital markets, thereby investigating the determinants of corporate capital structure. This is somehow surprising since lenders (in particular, banks and other financial institutions) crucially affect the cost of debt. ${ }^{4}$

To our knowledge, only a few papers have dealt with public policies and the supply side of capital market. ${ }^{5}$ Building upon the well-known contributions by Stiglitz and Weiss (1981) and de Meza and Webb (1987), Boadway and Keen (2006) generalize the findings of both papers by analyzing screening and signaling equilibria. In particular, they assume a continuum of potential firms, each with its own project characterized by a given probability and return in case of success, and a competitive bank sector. They investigate welfareimproving policy interventions. However, they admit that "it would be dangerous to draw

\footnotetext{
${ }^{1}$ This literature starts with Kraus and Litzenberger (1973) and has a relevant contribution by Leland (1994). More recently, for instance, Graham et al. (2011) find that firms with more debt and lower bond ratings in 1928 became financially distressed more frequently during the Depression, consistent with the trade-off theory of leverage and the information production role of credit rating agencies (cross-country works). Further evidence is provided by investigating tax effects on multinationals' capital structure (see e.g., the articles quoted in Miniaci et al., 2014).

${ }^{2} \mathrm{~A}$ useful survey of the effects of corporate finance on capital structure is provided by Harris and Raviv (1991). The textbook by Tirole (2006) provides a user-friendly analysis of all kinds of finance problems under asymmetric information. More recently, van Binsbergen et al. (2010) have shown that both tax and non-tax factors play a crucial role in determining the cost of debt. In particular, they point out that "default cost of debt amounts to approximately half of the total cost of debt, implying that agency costs and other nondefault costs contribute about half of the total ex ante costs of debt" (p. 2131).

${ }^{3}$ As shown by Strebulaev (2007) however, a negative relation between debt and profitability is also compatible with a dynamic trade-off model, where firms adjust their capital structure over time.

${ }^{4}$ For instance, recent evidence on screening technologies is provided by Uchida (2011) who employes a a dataset on Japanese small and medium-sized firms. Further evidence is provided by Berger and Black (2011) on the U.S. market. They show that large banks do not have equal advantages in all of these hard lending technologies and these advantages are not all increasing monotonically in firm size, contrary to the predictions of the current paradigm. Then, they analyze lines of credit without fixed-asset collateral to focus on relationship lending and confirm that small banks have a comparative advantage in relationship lending, but this appears to be strongest for lending to the largest firms.

${ }^{5}$ See, e.g., the surveys by Graham (2003) and Hanlon and Heitzman (2010). See also Graham (1999, 2000), Graham et al. (2008) and Kaplow (2008).
} 
any strong conclusions for policy" from their results and that "it is tempting to invoke the principle of insufficient reason to ... seek to impose any corrective tax or subsidy at all" (p. 501). In the same vein, Fuest and Tillessen (2005) study public assistance programs for entrepreneurial investment based on closed ended subsidies, namely, tax benefits granted only up to a certain absolute limit. To deal with the optimality of this policy they apply a three-stage model where banks offer loan contracts, then firms apply for the contract they prefer and finally banks decide whether to accept the application or not. Given this model, where both under- and over-investment are feasible, they show that under asymmetric information setting, banks distort investment in order to prevent mimicking. In this case, open ended (i.e., unlimited) taxes or subsidies are preferable. More recently Minelli and Modica (2009) use the Stiglitz-Weiss (1981) approach to find optimal policies under asymmetric information. By assuming the existence of banks with market power, they study three kinds of policy tools: interest rate subsidies; investment subsidies; loan guarantees. They then show that interest rate subsidies and loan guarantees are optimal to correct market equilibrium inefficiency. Simon (2012) has provided an explanation for a government to discriminate between debt and equity financing. Assuming that entrepreneurs are risk-averse, she shows that equity generates more surplus than debt, because it also provides insurance. If, therefore, the government aims at extracting surplus from entrepreneurs it would tax equity-financed income more heavily.

An interesting aspect is not analyzed by this literature. The effect of the business cycle on credit market conditions. As shown in Figure 1, the spread between the high-yield and the investment-grade interest rates on corporate bonds in the EU and US crucially depends on the business cycle. ${ }^{6}$ In particular, downturns lead to a sharp increase of this variable. We can thus say that the interest rate paid by corporations of different types is closer (more different) during a recovery (downturn). This piece of evidence has been disregarded by tax papers using asymmetric information.

Our paper departs from these articles in several respects. Firstly, we aim to set up a theoretical environment where five pieces of evidence are accounted for: i) the existence of a tax incentive to borrow (see e.g., Miniaci et al., 2014); ii) the negative relationship between leverage and profitability (see e.g., Miniaci et al., 2014); iii) the existence of asymmetric information in credit markets (see Gordon, 2010, and the papers cited herein); iv) the screening activity of lenders (see e.g., Stiglitz and Weiss, 1981) and v) the business cycle effects on the spread between the high-yield and the investment-grade interest rates on corporate loans (see Figure 1). In doing so, we consider both sides of capital markets. Secondly, we disregard the over- (under-) investment problem by assuming a given amount of investing firms. In doing so, we focus on financial choices and capital market equilibria, rather than on investment decisions. Thirdly, we will provide a welfare analysis and discuss corporate tax policy implications. Finally, we highlight and investigate the joint effect of the business cycle and of taxation on the credit market equilibrium.

Our two-period model assumes the existence of two types of risk-neutral firms that can invest even under taxation: bad firms, with lower success probability and expected returns, and good firms, with higher success probability and expected returns. The number of operating firms is given and all of them undertake an investment project, whose cost is normalized to unity. The firms can issue equity and/or apply for a loan from external lenders. We assume the existence of a capital market with at least two homogeneous risk-neutral lenders competing à la Bertrand. In particular they operate in an asymmetric

\footnotetext{
${ }^{6}$ The source is Global Financial Stability Report published by the International Monetary Fund in October 2013 and according to which both Stock Market volatility and the expected GDP growth rate are crucial determinants of bank lending standards. Of course, industry or firm outlook may matter as well.
} 


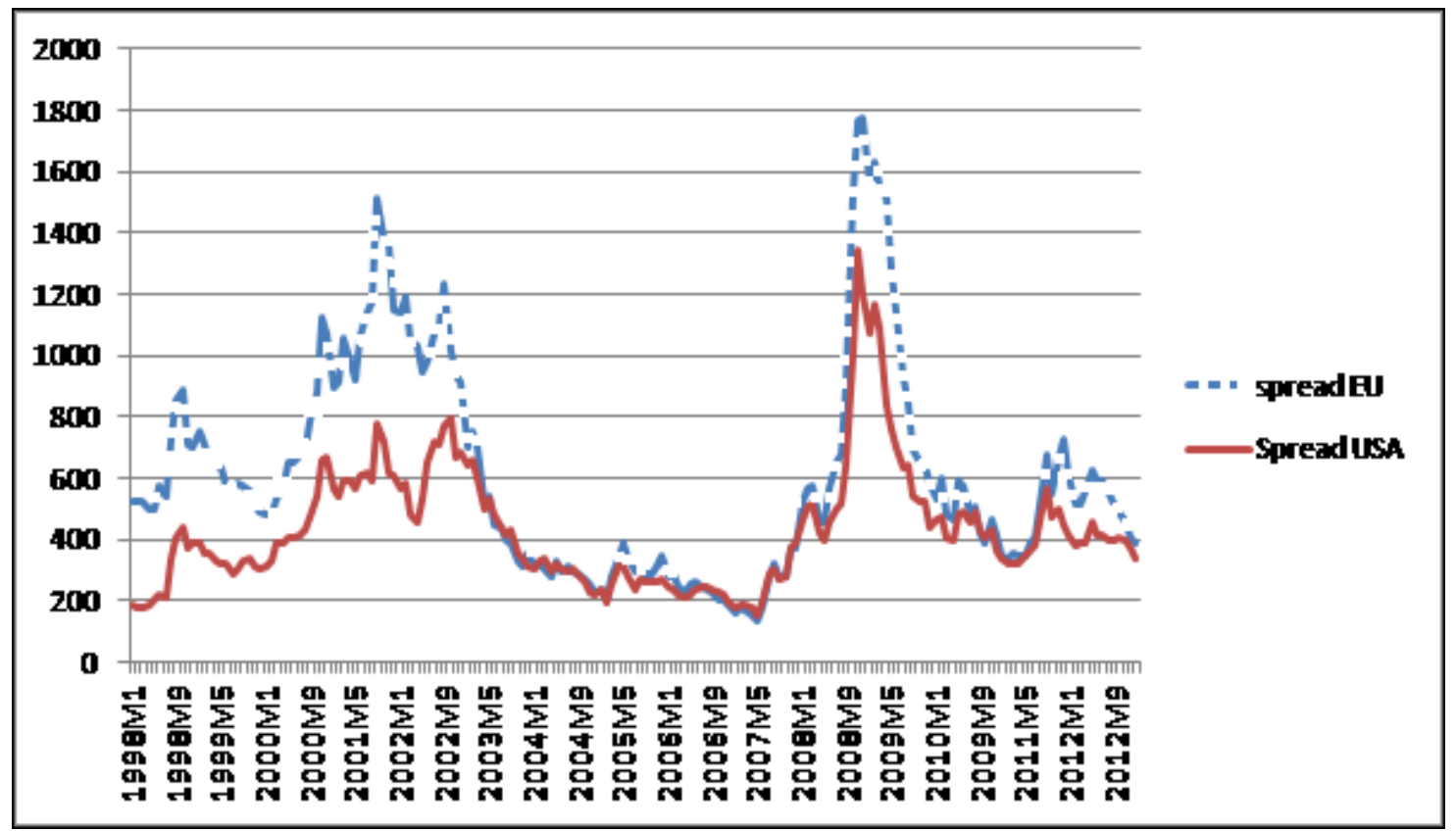

Figure 1: THE SPREAD BETWEEN THE HIGH-YIELD AND THE INVESTMENT-GRADE INTERest Rates on corporate bonds (Global Financial Stability Report, October, 2013)

information context, where firms' probability of success in unverifiable. Borrowing is regulated through a loan contract characterized by interest rate and amount of funding. In addition, we let the lenders decide whether to commit or not to the contract signed by firms. In case of non-commitment, the lenders can reject loan applications. The converse is true if they did commit. ${ }^{7}$ Given these assumptions we derive the following four main findings.

Firstly, if the portion of bad firms in the economy is relatively low a pooling equilibrium without commitment is found, where bad and good firms sign the same loan contract. Interestingly, the pooling equilibrium would disappear without the option of non-commitment, i.e., if the lenders were denied the option of rejecting firms' loan applications. By contrast, when there are more bad firms, a separating equilibrium arises, with or without commitment, where good firms are charged a lower interest rate but receive a smaller amount of external funding than bad firms. Put differently, firms with less pressing needs for cash (i.e., good ones) have a lower leverage.

Secondly, the above result crucially depends on corporate taxation, in that the threshold portion of bad firm below (above) which a pooling (separating) equilibrium exists is affected by the level of corporate tax rate.

Thirdly, our framework also allows us to study tax effects from a normative point of view. As will be shown, corporate tax rate increases are not necessarily welfare deteriorating.

Finally, we provide some comparative statics regarding the portion of bad firms. We prove that if the portion of bad firms increases (this is likely during a downturn) the increase in the corporate spread between the high-yield (i.e., bad firms) and the investment-

\footnotetext{
${ }^{7}$ The idea of contracts without commitment was first introduced by Wilson (1977) in the context of insurance markets with adverse selection. For a recent contribution, see Koufopoulos (2011).
} 
grade (good firms) interest rates, highlighted in Figure 1, is more likely to be observed in economies where the corporate tax rate is relatively high. Only in that case, the credit market may shift from a pooling to a separating equilibrium. Conversely, the decrease in the corporate spread following recoveries (i.e., decrease of the portion of bad firms in our model) is more likely to be observed in economies where the corporate tax rate is relatively low. This enables us to conclude that the effects of the business cycle on the credit market equilibrium may work not only through asymmetric information and the screening activity by banks, but also through taxation.

The structure of the paper is as follows. The model is laid out in Section 2, and describes financial choices under both symmetric and asymmetric information. Section 3 provides a welfare analysis. Section 4 derives comparative statics results. Section 5 summarizes our findings.

\section{The model}

Let us introduce a two-period model where a continuum of risk-neutral firms decide whether and how to finance risky investment projects. For simplicity, each project requires a fixed amount of money, which is normalized to 1 .

By assumption, there are two types of firms, denoted by $i=L, H$. Each project yields $A$ with probability $p_{i} \in(0,1)$ or $a<A$ with probability $\left(1-p_{i}\right)$. We let $0<p_{L}<p_{H}<1$. Accordingly, a firm $i$ 's expected return is equal to

$$
R_{i}=p_{i} A+\left(1-p_{i}\right) a,
$$

with $R_{H}>R_{L}$. Firms earning the expected return $R_{H}\left(R_{L}\right)$ are defined good (bad) firms. A proportion $\lambda \in(0,1)$ of firms is bad. The remaining proportion $(1-\lambda)$ is good. Our firms have no cash holding and have access to two sources of finance: they issue equity $E \in[0,1]$ at zero cost and/or apply for a loan $B \in[0,1]$ from external lenders.

Lenders operate in a competitive screening environment. For this reason, we assume the existence of a capital market with at least two homogeneous risk-neutral lenders. The lenders compete à la Bertrand and are unable to observe firms' good-state-return probability $p_{i}$. Borrowing is regulated through a loan contract characterized by a pair $\{\rho, B\}$. Parameter $\rho$ denotes the interest rate and $B$ the amount lent. In addition, the contract contains parameter $k \in\{0,1\}$, which specifies whether the lenders are committed to the contract, $k=1$, or not committed, $k=0$. If $k=1$ the lenders cannot reject applications for the contracts offered. Instead, if $k=0$, the lenders keep the right to do it. Finally, if the firms are not able to repay, the lenders become shareholders at zero cost.

Let us next introduce the following two assumptions.

Assumption 1 The bad-state return, a, belongs to interval $[-1, r)$, where $r>0$ is the risk-free interest rate.

Assumption 2 The good-state return, $A$, is weakly higher than $\underline{A}=\frac{r-\left(1-p_{L}\right) a}{p_{L}}$.

Assumption 1 states that the bad-state gross return $1+a$ can be neither less than zero nor higher than $1+r$. In the former case a "black swan" event is excluded, where returns are less than $-100 \%$. In the latter case the upper bound holds by definition of bad-state return; indeed, a state of nature is bad if a firm's return is less than the opportunity cost $r$. The inequality $A \geq \underline{A}$ in Assumption 2 means that $\left(R_{H}>\right) R_{L} \geq r$.

Let us finally introduce taxation. By assumption, a firm's profit is taxed at a corporate rate $t \in(0,1]$. For simplicity, we also introduce the following: 
Assumption 3 Lenders are tax-exempt.

Assumption 3 can be justified by the fact that the tax burden on capital income is relatively low or even close to zero in most cases. As pointed out by Cooper and Nyborg (2008), moreover, default risk entails that the evaluation of debt "depends upon the tax position of insolvent firms and the tax treatment of debt write-downs" (p. 366). In particular, they refer to the tax treatment of debt write-downs in the USA. According to the law, no tax liability is accounted for if the insolvent firm's liabilities exceed its assets. ${ }^{8}$ Since we aim to focus on a real default case rather than a debt restructuring one, Assumption 3 fits well with our aim. ${ }^{9}$

The timing of events is as follows.

\section{Before time 0:}

Stage 1 Nature selects the risk type of each firm.

Stage 2 The Government sets the corporate tax rate $t$.

\section{At time 0:}

Stage $1 N \geq 2$ lenders compete à la Bertrand by simultaneously offering loan contracts to the firms. Each contract is a pair $\left\{\rho_{i} ; B_{i}\right\}$, plus the commitment parameter $k_{i}$, $i=L, H$. Since there are only two types of firms, the lenders offer at most a pair of contracts.

Stage 2 Firms decide whether to invest in the project. If so, they decide whether to accept a loan contract. If they do not, they issue equity $E$ to finance their project.

Stage 3 After observing the contracts offered by rival lenders and those chosen by the firms, the lenders who did not commit to their contracts at Stage 1, i.e., those who chose $k_{i}=0$, decide whether to withdraw the contract or not. If a contract is withdrawn, the firms which signed it decide whether to invest and, if so, they resort to equity $E$. All the other agreements, i.e., contracts with or without commitment that were not withdrawn, are signed by the parties.

Stage 4 Each firm $i$ invests the amount

$$
E_{i}+B_{i}=1
$$

At time 1: Each firm yields either $A$ or $a$. If it has enough cash, it repays the lenders.

Given these assumptions, we will study pure-strategy subgame perfect Nash equilibria (SPNEs) of the four-stage game played by lenders and firms at time $0 .{ }^{10}$ In principle, three types of pure-strategy SPNEs might be a solution to the game:

(i) Separating equilibria, when the two types of firms sign different loan contracts.

(ii) Pooling equilibria, when bad and good firms accept the same loan contract.

\footnotetext{
${ }^{8}$ Notice that the tax treatment of debt write-downs is similar in many other countries.

${ }^{9}$ On the cost of corporate debt see, e.g., van Binsbergen et al. (2010).

${ }^{10}$ One can show that the set of SPNEs is equivalent to that of perfect Bayesian equilibria in our competitive screening game.
} 
(iii) Rationing equilibria, when one type of firms signs a contract, while the other type signs no contract.

Before proceeding, it is useful to invoke a Bertrand argument to state the following

Claim 1 In a pooling or rationing equilibrium the lenders earn zero profit. In a separating equilibrium the lenders earn zero profits on each type of contract.

\subsection{Symmetric information}

Let us consider the benchmark case where probability $p_{i}$ is verified by the lenders.

Under Bertrand competition, studying the SPNEs of the above four-stage game amounts to solve the following problem: at time 0 , any firm $i$ chooses $E_{i}$ and $B_{i}$ to maximize its net present value, subject to the the lenders' zero-profit condition.

In Appendix A we show that the firms' net present value is maximized under full debt-finance. More precisely,

Lemma 1 Under symmetric information, the SPNE of the four-stage game played by lenders and firms at time 0 is a separating equilibrium where the lenders break even and fully finance the project by offering loan contracts with or without commitment to firms. In symbols

$$
\left\{\rho_{i}^{*}, B_{i}^{*}\right\}=\left\{\frac{r-\left(1-p_{i}\right) a}{p_{i}}, 1\right\}, k_{i}^{*}=\{0,1\}, \text { and } E_{i}^{*}=0 .
$$

This result crucially depends on the tax deductibility of interest expenses. Under full debt finance, a firm's positive profit net of the interest expenses is taxed at the corporate tax rate $t$. Therefore, the more the firm borrows, the lower the tax liability is. Under equity finance however no tax saving is ensured. More precisely, in Appendix A we show that the probability of firms' default is zero if $B_{i} \in\left[0, \frac{1+a}{1+r}\right]$ with $\frac{1+a}{1+r} \in[0,1)$ under Assumption 1, $\forall i$, while it is equal to $0<\left(1-p_{i}\right)<1$, hence unaffected by the level of $B_{i}$, when $B_{i} \in\left(\frac{1+a}{1+r}, 1\right], \forall i .^{11}$ Since the default probability is independent from the leverage ratio $\frac{B_{i}}{B_{i}+E_{i}}=B_{i}$, full debt finance is always the best choice under symmetric information.

\subsection{Asymmetric information}

Let us next turn to the asymmetric information. In that case, the lenders cannot verify the firms' type and just know the proportion $\lambda$ of bad firms.

Remember that a firm's ability to repay the debt depends on the level of borrowing $B$. In particular, both types of firms can repay the lenders if $B$ is low enough, i.e., if $B \in\left[0, \frac{1+a}{1+r}\right]$. In this case, the lenders' break-even interest rate is equal to the risk-free one, $r$. If however the leverage ratio is high enough, i.e., $B_{i} \in\left(\frac{1+a}{1+r}, 1\right]$, the probability of repayment is $p_{i}$. Given the risk of default, the lenders' break-even interest rate is $\rho>r$.

In what follows, we will first focus on the area $B_{i} \in\left(\frac{1+a}{1+r}, 1\right]$, thereby solving the fourstage game played by lenders and firms at time 0 . Then, we will show that the equilibria found for $B_{i} \in\left(\frac{1+a}{1+r}, 1\right]$ dominate the only candidate SPNE in the $B \in\left[0, \frac{1+a}{1+r}\right]$ area.

\footnotetext{
${ }^{11}$ The latter result departs from the standard Trade-Off Theory (see, e.g., Kraus and Litzenberger, 1973, and Leland, 1994). This will allow us to focus on tax effects under asymmetric information with a tractable framework.
} 
Following a consolidated tradition, we adopt a graphical approach by considering a $(\rho, B)$ plane, with $B \in\left(\frac{1+a}{1+r}, 1\right]$ and $\rho>r$. To do so we will define five curves, which are drawn in Figure 2: ${ }^{12}$

1. a lenders' zero-profit curve for each separating contract, that is $O H$ (contract with good firms) and $O L$ (contract with bad firms), where point $O$ is characterized by $\rho=r$ and $B=\frac{1+a}{1+r}$;

2. a lenders' zero-profit curve for a pooling contract, denoted by $O P$;

3. a good firms' indifference curve, denoted by $H^{\prime} H^{\prime \prime}$, and a bad firms' one, denoted by $L L^{\prime}$.

The lenders' profit function is given by

$$
p_{i}\left(1+\rho_{i}\right) B_{i}+\left(1-p_{i}\right)(1+a)-(1+r) B_{i} .
$$

As pointed out, firm $i$ repays debt, i.e., $\left(1+\rho_{i}\right) B_{i}$, with probability $p_{i}$. Of course, the probability of default is $\left(1-p_{i}\right)$. In this case the lenders seize $1+a$. Term $(1+r) B_{i}$ is the lenders' opportunity cost of lending the amount $B_{i} \cdot{ }^{13}$

In Appendix B.1, we show that: (i) the three lenders' zero-profit curves, $O H, O L$, and $O P$, are upward sloping in the $(\rho, B)$ plane and that the lenders are better-off (worse-off) when moving south-east (north-west) from any point on the curves; (ii) $\mathrm{OH}$ is steeper than $O L$. Result (i) is due to the fact that $\rho$ enters positively in (3), whilst $B$ enters negatively. The reasoning for result (ii) is as follows. For any given increase in $\rho$, the lenders' zero-profit condition, i.e., $(3)=0$, holds if $B$ is also increasing. It is worth noting that such an increase must be higher along $O H$ because $\rho$ is paid with higher probability by good firms. Finally, the pooling zero-profit curve $O P$ is a linear combination of $O H$ and $O L$. It collapses to $O H$ when all firms are good, $\lambda=0$, and to $O L$ when all firms are bad, $\lambda=1$. Intuitively, $O P$ is increasing in $\rho$ and flatter (steeper) than $O H(O L)$.

Let us next focus on the firms' indifference curves. Firm $i$ 's net present value is given by

$$
N P V_{i}=-\left(1-B_{i}\right)+p_{i} \frac{(1-t)\left(A-\rho_{i} B_{i}\right)+\left(1-B_{i}\right)}{1+r},
$$

where $\left(1-B_{i}\right)$ denotes the equity issue, $\frac{1}{1+r}$ is the discount factor and $\left(A-\rho_{i} B_{i}\right)$ is the relevant tax base in the event of success. ${ }^{14}$ In Appendix B.2 we focus on the firms' indifference curves $H^{\prime} H^{\prime \prime}$ and $L L^{\prime}$ and show that: (i) the indifference curves are upward sloping and that the firms are better-off (worse-off) when moving north-west (south-east) from any point on the same curves; this is due to the fact that $\rho$ enters negatively and $B$ enters positively in $N P V_{i}$; (ii) good firms' indifference curves are steeper than bad firms' curves because an increase in $\rho$ entails higher costs for good firms since they repay with higher probability; as a result, good firms must borrow a larger amount of $B$ in order to be indifferent.

Let us next analyze the pure-strategy SPNE of the four-stage game played by lenders and firms.

\footnotetext{
${ }^{12}$ In all Figures the benchmark parameter values are: $p_{L}=.95 ; p_{H}=.99 ; r=.05 ; A=.5 ; a=-.1$; $t=.3 ; \lambda=0.5$.

${ }^{13}$ For further details see Appendix A.

${ }^{14}$ See Appendix A for more details.
} 


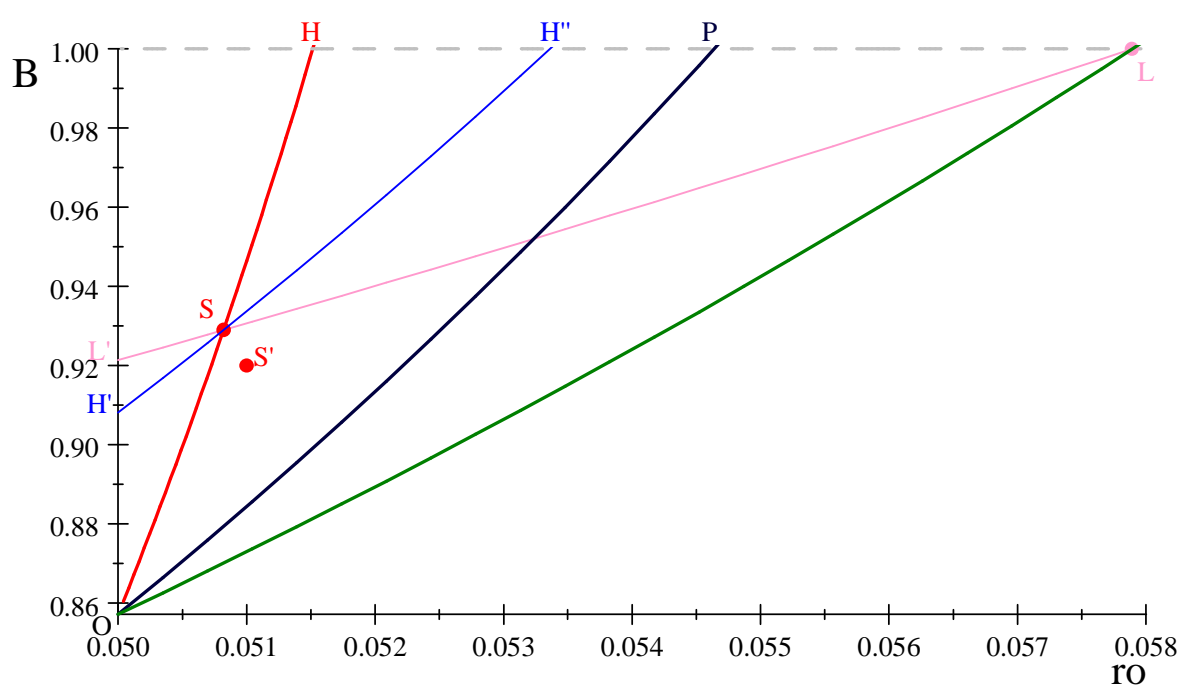

Figure 2: Separating EQUilibrium

Separating equilibrium. As a first step, we prove that an equilibrium where separating contracts are signed exists only if the share $\lambda$ of bad firms is high enough.

Lemma 1 shows that a separating equilibrium $\left\{\rho_{i}^{*}, 1\right\}$ exists under symmetric information: in this case the lenders earn zero profit by offering first-best type-dependent contracts with or without commitment. When however $p_{i}$ is not observed by the lenders, Lemma-1 first-best contracts cannot be an equilibrium. Given $\rho_{L}^{*}>\rho_{H}^{*}$, bad firms would prefer contract $\left\{\rho_{H}^{*} ; 1\right\}$ to contract $\left\{\rho_{L}^{*} ; 1\right\}$. The lenders want to prevent bad firms from choosing $H$. For this reason, they offer $L$ to bad firms and a contract to good firms which is worse than $H=\left(\rho_{H}^{*} ; 1\right)$.

According to Claim 1, lenders earn zero profits on each per-type contract in a separating equilibrium, if any. Hence, the equilibrium separating contract offered to good firms must lie on the zero-profit curve $O H$. We argue that the separating equilibrium consists of two contracts: contract $L=\left(\rho_{L}^{*} ; 1\right)$ for bad firms and contract $S=\left(\rho_{S} ; B_{S}\right)$ for good ones. As shown in Figure 2, point $S$ is given by the intersection between $L^{\prime} L$ (the bad firms' indifference curve) and $O H$ (the lenders' zero-profit curve for good firms). It is worth noting that contract $L$ is unique under Bertrand competition. Similarly, contract $S$ is unique because any contract lying on $O S$ would be undercut by the other lenders and any contract lying on $S H$ would also be chosen by bad firms. In symbols, contract $S$ is given by

$$
\rho_{S}=\frac{r\left(p_{H}-p_{L}\right)(1+a)+t\left(1+r-p_{H}\right)\left(r-a+a p_{L}\right)}{\left(p_{H}-p_{L}\right)(1+a)+t\left[p_{H}(r-a)+p_{L}\left(1+a-p_{H}\right)\right]}<\rho_{H}^{*}
$$

and

$$
B_{S}=\frac{\left(1-p_{H}\right)(1+a)}{1+r-p_{H}\left(1+\rho_{S}\right)}<1
$$

Substituting $\rho_{S}$ and $B_{S}$ into (4), with $i=H$, gives the good firms' $N P V$ under contract $S=\left\{\rho_{S} ; B_{S}\right\}$

$$
N P V_{H, S}=-\left(1-B_{S}\right)+p_{H} \frac{(1-t)\left(A-\rho_{S} B_{S}\right)+\left(1-B_{S}\right)}{1+r} .
$$


Similarly, substituting $\rho_{L}^{*}$ and $B_{L}=1$ into (4), with $i=L$, gives the bad firms' $N P V:^{15}$

$$
N P V_{L, S}=p_{L} \frac{(1-t)\left(A-\rho_{L}^{*}\right)}{1+r}
$$

Quite interestingly, the separating equilibrium $(L, S)$ vanishes if the share $\lambda$ of bad firms is low enough. The intuition is straightforward if we look at the pooling contract $P=\left\{\rho_{P} ; 1\right\}$, where ${ }^{16}$

$$
\rho_{P}=\frac{r-a\left[\lambda\left(1-p_{L}\right)+(1-\lambda)\left(1-p_{H}\right)\right]}{\lambda p_{L}+(1-\lambda) p_{H}}
$$

It is easy to see that $\rho_{P}$ is increasing in $\lambda$, i.e.,

$$
\frac{\partial \rho_{P}}{\partial \lambda}=\frac{\left(p_{H}-p_{L}\right)(r-a)}{\left[\lambda p_{L}+(1-\lambda) p_{H}\right]^{2}}>0 .
$$

This is due to the fact that the lenders' expected repayment rate decreases with the number of bad firms. Therefore, contract $P$ turns out to be particularly appealing as $\lambda$ approaches 0 and may be preferred by good firms to the separating contract $S$.

Figure 3 provides a graphical proof of the nonexistence of the separating equilibrium when $\lambda$ is low enough. $O P$ is depicted for $\lambda=.2$, instead of the initial value, .5. As $\lambda$ diminishes the pooled zero-profit curve $O P$ rotates counterclockwise and may intersect curve $H^{\prime} H^{\prime \prime}$ at a point $M$ with $B_{M}<1$. In this case, a profitable deviation is available to at least one lender when all rivals offer the pair of separating contracts $(L, S)$. A new contract $D=\left\{\rho_{D} ; B_{D}\right\}$ with $k=1$ (i.e., with commitment) may be offered. This contract lies in area $M P H^{\prime \prime}$, where both types of firms are better-off and the lenders make positive profits. Accordingly, all firms sign contract $D$ because at least one lender is committed to it.

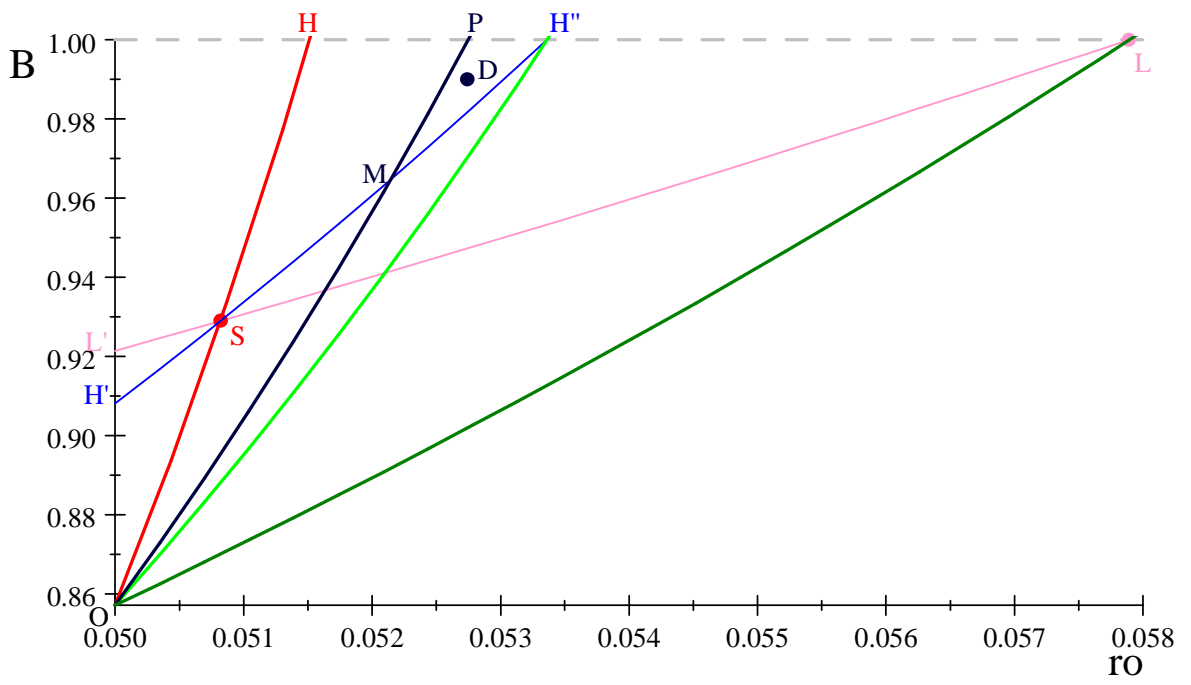

Figure 3: No SEPARATING EQUILIBRIUM When $\lambda<\lambda^{\circ}$

\footnotetext{
${ }^{15}$ In Appendix B.3 we check that both good and bad firms' participation constraints are fulfilled at the separating equilibrium $(L, S)$.

${ }^{16}$ See Appendix B.4 for computations.
} 
The minimum share $\lambda$, below which the separating equilibrium $(L, S)$ fails to exist, is given by the intersection between the pooled zero-profit line $O P$ and $H^{\prime} H^{\prime \prime}$ at $B=1$. As shown in Appendix B.5, we obtain

$$
\lambda^{\circ}=\frac{p_{H} t\left(1+r-p_{H}\right)}{(1+r)\left(p_{H}-p_{L}\right)+p_{H} t\left(1+r-p_{H}\right)} \in(0,1) .
$$

Pooling equilibrium. A pooling equilibrium contract, if any, must lie on the pooled zero-profit curve $O P$ according to Claim 1. In Appendix B.6 we prove that the only candidate pooling equilibrium contract is $P=\left(\rho_{P} ; 1\right)$.

Let us next show that when the separating contracts $(L, S)$ do not represent an equilibrium, this occurs when $\lambda<\lambda^{\circ}$, the agreement $P=\left\{\rho_{P} ; 1\right\}$ without commitment, i.e., $k=0$, is the unique pooling equilibrium. To do so, we introduce Figure 4 , which is based on Figure 3, and depict two new curves: $L^{\prime} P$ is bad firms' and $H^{\prime} P$ is good firms' indifference curve through contract $P$.

First notice that if all lenders offer $P=\left\{\rho_{P} ; 1\right\}$ with commitment, $k=1$, to both types, at least one lender can propose a rationing contract $B=\left(\rho_{B} ; B_{B}\right)$. This is a profitable deviation since $B$ lies in the GFP area. It is thus accepted only by good firms and lies south-east of the zero-profit curve $O H$. As a result, $P=\left\{\rho_{P} ; 1\right\}$ with commitment is not an equilibrium solution.

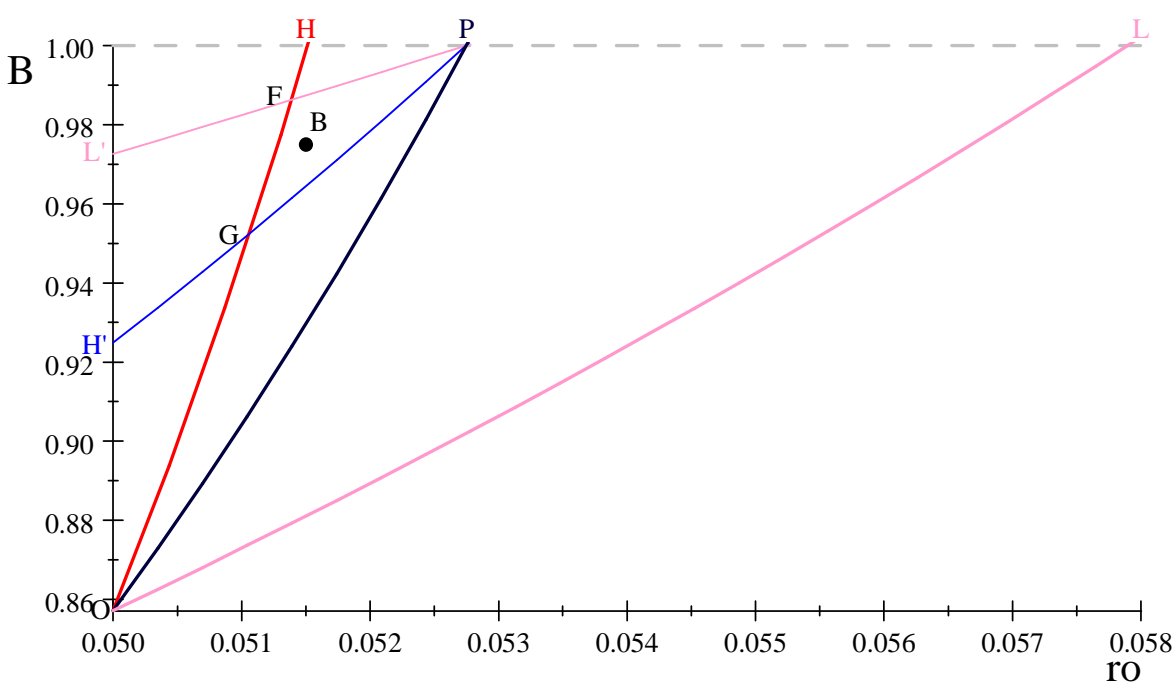

Figure 4: Pooling equilibrium without commitment when $\lambda<\lambda^{\circ}$

It is worth noting that no contract in area $G F P$, e.g., $B$, is profitable if all lenders offer $P=\left\{\rho_{P} ; 1\right\}$ without commitment, i.e., with $k=0$. Since contract $B$ attracts only good firms, $P$ is chosen by bad firms with the effect that the lenders face losses. As a result, at Stage 3, contract $P$ is withdrawn. This is possible because $P$ is without commitment. Anticipating that, at Stage 2 also bad firms choose contract $B$ since it is the only available. ${ }^{17}$ In this case, $B$ causes losses to the lenders since it lies to the north-west of the pooled zero-profit curve $O P$. We can therefore conclude that there is no profitable deviation from $P$ and that contract $P$ will not be withdrawn at Stage 3 .

\footnotetext{
${ }^{17}$ One can easily check that contract $B$ is preferred by the firms to their outside option.
} 
Given this result, we can substitute $\rho_{P}$ and $B_{P}=1$ into (4) to obtain firm $i$ 's $N P V$ when the equilibrium pooling contract $P=\left\{\rho_{P} ; 1 ; 0\right\}$ is signed:

$$
N P V_{i, P}=p_{i} \frac{(1-t)\left(A-\rho_{P}\right)}{1+r} .
$$

Finally, one can easily check that at contract $P$ the participation constraint of both type of firms is fulfilled.

In Appendix B.7 we demonstrate that no rationing contract, when only one type of firms signs the agreement, exists at equilibrium.

We sum up the above results in the following:

Proposition 1 Under asymmetric information:

(i) If the share of bad firms in the economy is relatively low, $\lambda<\lambda^{\circ}$, the unique SPNE of the four-stage game played by lenders and firms at time 0 is a pooling equilibrium, where both good and bad firms sign contract $P=\left\{\rho_{P} ; 1\right\}$ and the lenders are not committed, i.e., $k=0$.

(ii) If the share of bad firms in the economy is relatively high, $\lambda \geq \lambda^{\circ}$, the unique SPNE is a separating equilibrium, where bad firms sign their first best contract $L=\left\{\rho_{L}^{*} ; 1\right\}$, whilst good firms sign contract $S=\left\{\rho_{S} ; B_{S}\right\}$, with $\rho_{S}<\rho_{H}^{*}\left(<\rho_{L}^{*}\right)$ and $B_{S}<1$, and issue equity $E_{S}=1-B_{S}$. The lenders may be committed or nor committed to contracts $L$ and $S$, i.e., $k=\{0,1\}$.

Note that for any given $t$ bad firms prefer the pooling contract $P$ to the separating contract $L$. Both agreements entail full debt finance, but the former prescribes a lower interest rate because bad firms are cross-subsidized by good firms. We can thus say that the good firms' equilibrium strategy drives the results of Proposition 1. Moreover, when few bad firms are present in the economy, $\lambda<\lambda^{\circ}$, the pooling interest rate $\rho_{P}$ is relatively low because the lenders expect a relatively high average probability of debt repayment, $\lambda p_{L}+(1-\lambda) p_{H}$. For this reason the good firms select contract $P$. In this context no firm is credit rationed, in that they receive the same amount of borrowing, 1 , as that obtained under symmetric information. When however inequality $\lambda \geq \lambda^{\circ}$ holds, interest rate $\rho_{P}$ becomes too high for good firms. For this reason they prefer the separating contract $S$. Though they are credit rationed, $B_{S}<B_{P}=1$, they pay a much lower interest rate, $\rho_{S}<\rho_{P} \cdot{ }^{18}$

It is worth pointing out that the two SPNEs in Proposition 1 dominate the only candidate SPNE in the area $B \in[0,(1+a) /(1+r)]$ : see Appendix B.8. Therefore we can restrict our analysis to $B_{i} \in((1+a) /(1+r), 1]$ without loss of generality.

\section{Welfare analysis}

So far we have focused on the positive point of view. In order to better understand tax effects we also need to investigate the normative point of view. For this reason, in this section we provide a welfare analysis. We adopt a utilitarian approach by defining welfare $W$ as the sum of lenders' profits and firms' $N P V s$. The Government's tax revenue is denoted by $T$.

The equilibrium welfare of the economy is thus given by

$$
W_{j}=\lambda N P V_{L, j}+(1-\lambda) N P V_{H, j}+0,
$$

\footnotetext{
${ }^{18}$ Note that $\rho_{S}$ is unaffected by $\lambda$, thus the difference $\rho_{P}-\rho_{S}$ increases with $\lambda$.
} 
where: $j=P, S$ denotes the type of equilibrium, either pooling or separating; $N P V_{i, j}$ is firm $i$ 's $N P V$ under equilibrium $j$; 0 measures the equilibrium profits of our competitive lenders.

As shown in Proposition 1, depending on the value of $\lambda$, we have two possible outcomes.

1. If $\lambda<\lambda^{\circ}$, the SPNE is pooling. Substituting (12) into (13) gives the pooling equilibrium welfare

$$
W_{P}(t)=\left[\lambda p_{L}+(1-\lambda) p_{H}\right] \frac{(1-t)\left(A-\rho_{P}\right)}{1+r}
$$

and the relevant tax revenue

$$
T_{P}(t)=\left[\lambda p_{L}+(1-\lambda) p_{H}\right] \frac{t\left(A-\rho_{P}\right)}{1+r} .
$$

2. If $\lambda \geq \lambda^{\circ}$, a separating SPNE exists and therefore welfare is

$$
\begin{gathered}
W_{S}(t)=\lambda \frac{p_{L}(1-t)\left(A-\rho_{L}^{*}\right)}{1+r}+ \\
(1-\lambda) \frac{p_{H}(1-t)\left(A-\rho_{S} B_{S}\right)-\left(1+r-p_{H}\right)\left(1-B_{S}\right)}{1+r},
\end{gathered}
$$

after substituting (7) and (8) into (13). The separating equilibrium tax revenue is instead

$$
T_{S}(t)=\lambda \frac{p_{L} t\left(A-\rho_{L}^{*}\right)}{1+r}+(1-\lambda) \frac{p_{H} t\left(A-\rho_{S} B_{S}\right)}{1+r} .
$$

As shown in Appendix C.1, both the pooling and separating welfare functions, i.e., $W_{P}(t)$ and $W_{S}(t)$, are continuous and monotonically decreasing in the corporate tax rate $t$. Intuitively, taxation affects negatively the equilibrium firms' $N P V s$. Moreover, the sums of welfare and tax revenue under both equilibria, $W_{S}+T_{S}$ and $W_{P}+T_{P}$, are independent on $t$ since

$$
\begin{aligned}
& W_{S}+T_{S}=W_{P}+T_{P}= \\
& \frac{\left[\lambda p_{L}+(1-\lambda) p_{H}\right] A+\left\{1-\left[\lambda p_{L}+(1-\lambda) p_{H}\right]\right\} a-r}{1+r} \text { for any } t
\end{aligned}
$$

We infer that the equilibrium values of tax revenue, $T_{S}(t)$ and $T_{P}(t)$, are continuous and monotonically increasing in $t$.

Given these results, we let the Government maximize welfare subject to a minimum tax revenue needed by Tax Authorities, denoted by $T^{*}(t)$ :

$$
\begin{gathered}
\max _{t} W_{j}(t) \\
\text { s.t. } T_{j}(t) \geq T^{*}(t) .
\end{gathered}
$$

We provide a graphical solution to problem (19). To this aim we first differentiate the threshold portion $\lambda^{\circ}$ in (11) w.r.t. $t$

$$
\frac{\partial \lambda^{\circ}}{\partial t}=\frac{p_{H}\left(p_{H}-p_{L}\right)(1+r)\left(1+r-p_{H}\right)}{\left[(1+r)\left(p_{H}-p_{L}\right)+p_{H} t\left(1+r-p_{H}\right)\right]^{2}}>0 .
$$

In Figure 5 we draw the threshold $\lambda^{\circ}$ as an increasing function of $t$.

It is easy to check that $\lambda^{\circ}=0$ when $t=0$, i.e., $\lambda^{\circ}(0)=0$. When however $t=1$, the inequality $\lambda^{\circ}(1)<1$ holds, i.e.,

$$
\lambda^{\circ}(1)=\frac{p_{H}\left(1+r-p_{H}\right)}{(1+r)\left(p_{H}-p_{L}\right)+p_{H}\left(1+r-p_{H}\right)} \in(0,1) .
$$




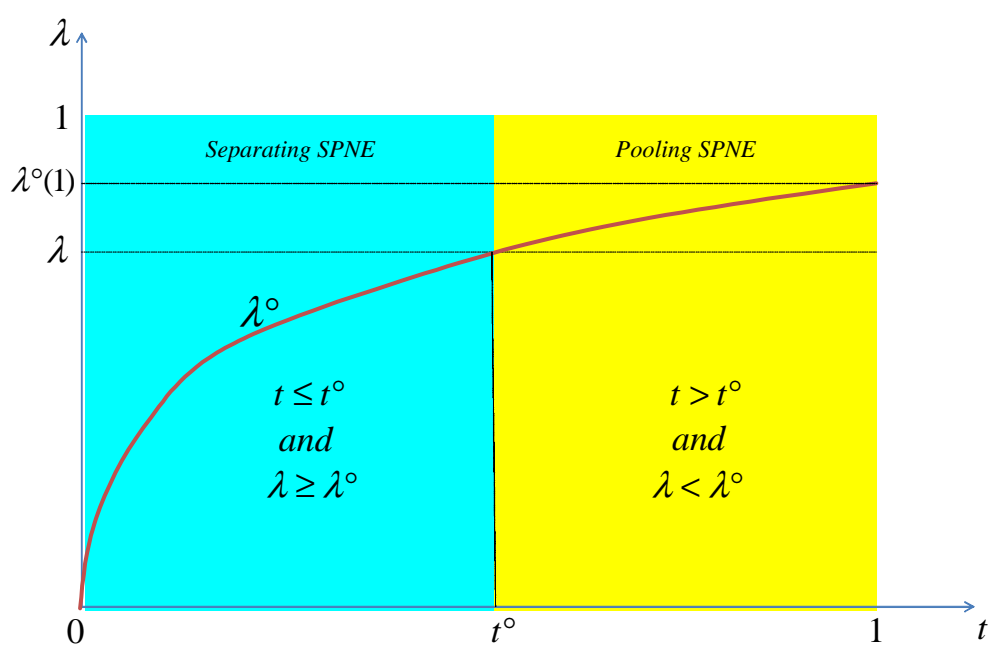

Figure 5: Threshold $\lambda^{\circ}$ AS A FUnCtion of $t$

As a result, if the actual proportion $\lambda$ of bad firms is higher than or equal to $\lambda^{\circ}(1)$, the separating contracts $L$ and $S$ are the only SPNE of the four-stage game played by lenders and firms at time 0 ; indeed $\lambda \geq \lambda^{\circ}$ for any $t$.

By contrast, when the actual proportion $\lambda$ of bad firms is lower than $\lambda^{\circ}(1)$, as depicted in Figure 5, the level of corporate tax rate $t$ affects the equilibrium described in Proposition 1. To better understand tax effects, let us calculate the tax rate ensuring that cut-off value $\lambda^{\circ}$ equals the actual proportion $\lambda$ of bad firms. To this aim, we set $\lambda^{\circ}=\lambda$ and solve (11) for $t$, thus obtaining the threshold corporate tax rate

$$
t^{\circ}=\frac{\lambda}{1-\lambda} \frac{p_{H}-p_{L}}{p_{H}} \frac{1+r}{1+r-p_{H}} .
$$

Note that, rather obviously, $t^{\circ}<1 \Leftrightarrow \lambda<\lambda^{\circ}$ (1). According to Figure 5, if the Tax Authority selects $t \leq t^{\circ}$, then the cut-off $\lambda^{\circ}$ is weakly lower than the actual fraction of bad firms and the SPNE is separating. By contrast, if the Tax Authority raises $t$ beyond $t^{\circ}$, $\lambda^{\circ}$ becomes higher than $\lambda$ and the SPNE is pooling. We highlight that the Tax Authority can affect the credit market equilibrium described in Proposition 1 in the following:

Proposition 2 For any given portion $\lambda$ of bad firms in the economy, if the Tax Authority sets $t \leq t^{\circ}$, the SPNE is separating; if $t>t^{\circ}$, the SPNE is pooling.

Recalling it is the good firms' equilibrium behavior that determines the credit market outcome, the intuition behind this result is as follows. The higher $t$, the more appealing the pooling contract $P=\left\{\rho_{P} ; 1\right\}$ for good firms, since it entails full debt finance, $B_{P}=1$, which gives increasingly large tax savings in terms of interest deductibility.

In Figure 6 we represent problem (19) by depicting welfare $W_{j}(t)$ and tax revenue as a function of $t$ when $\lambda<\lambda^{\circ}(1)$ or, equivalently, $t^{\circ}<1$. $T_{S}(t)$ and $T_{P}(t)$ denote tax revenue under separating and pooling equilibrium, respectively.

First note that by definition of $t^{\circ}$ good firms are indifferent between the separating contract $S$ and the pooling one $P$ when $t=t^{\circ}$. In symbols, $N P V_{H, S}\left(t^{\circ}\right)=N P V_{H, P}\left(t^{\circ}\right)$. By contrast, bad firms are strictly better-off when choosing the pooling contract $P$ instead 


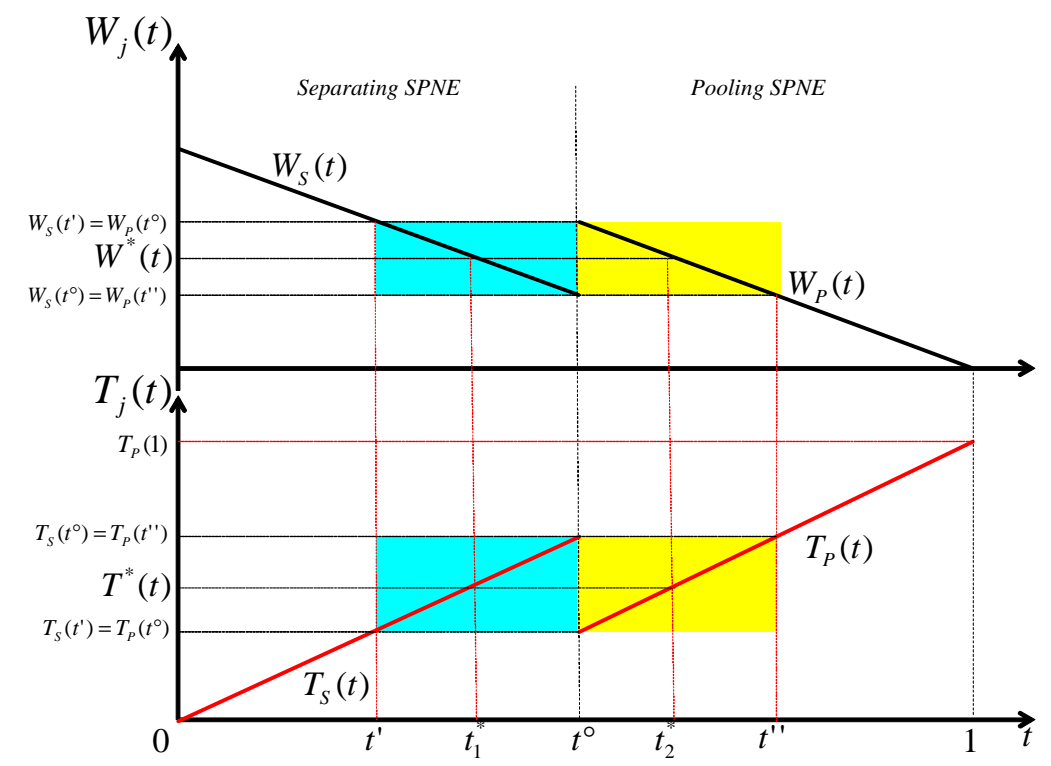

Figure 6: Equilibrium welfare and tax Revenue as a function of $t$ When $\lambda<$ $\lambda^{\circ}(1)$

of the separating one $L, N P V_{L, P}\left(t^{\circ}\right)>N P V_{L, S}\left(t^{\circ}\right)$. Indeed, both contracts offer full debt finance, but the former requires a lower interest rate, $\rho_{P}<\rho_{L}^{*}$. We can correctly conclude that at $t=t^{\circ}$ the equilibrium welfare is higher under the pooling equilibrium, i.e., $W_{P}\left(t^{\circ}\right)>W_{S}\left(t^{\circ}\right)$.

In Appendix C.2 we also prove that $W_{S}(0)>W_{P}\left(t^{\circ}\right)$ and $W_{S}\left(t^{\circ}\right)>W_{P}(1)=0$. Since $W_{S}(t)$ is continuous and monotonically decreasing in $t \in\left(0, t^{\circ}\right)$, we can state that a corporate tax rate $t^{\prime} \in\left(0, t^{\circ}\right)$ exists such that the equality $W_{S}\left(t^{\prime}\right)=W_{P}\left(t^{\circ}\right)$ exists. Note that $W_{S}\left(t^{\prime}\right)=W_{P}\left(t^{\circ}\right)$ implies $T_{S}\left(t^{\prime}\right)=T_{P}\left(t^{\circ}\right)$ given (18). Similarly, a tax rate $t^{\prime \prime} \in\left(t^{\circ}, 1\right]$ exists such that the equalities $W_{S}\left(t^{\circ}\right)=W_{P}\left(t^{\prime \prime}\right)$ and $T_{S}\left(t^{\circ}\right)=T_{P}\left(t^{\prime \prime}\right)$ hold.

Let us next analyze the solutions to the Government's problem, by assuming that, for any target tax revenue, the constraint in (19) is always binding at the optimum, since $W_{j}(t)$ decreases with $t$, whilst $T_{j}(t)$ increases with $t$.

1. If the target tax revenue $T^{*}(t)$ belongs to the interval $\left(T_{S}\left(t^{\prime}\right), T_{S}\left(t^{\circ}\right)\right]$, like in Figure 6 , there are two different tax rates solving problem (19): $t_{1}^{*} \in\left(t^{\prime}, t^{\circ}\right)$ and $t_{2}^{*} \in\left(t^{\circ}, t^{\prime \prime}\right)$, where $T^{*}(t)=T_{S}\left(t_{1}^{*}\right)=T_{P}\left(t_{2}^{*}\right)$ and welfare is $W^{*}(t)=W_{S}\left(t_{1}^{*}\right)=W_{S}\left(t_{2}^{*}\right)$.

2. If $T^{*}(t)$ belongs to either the $\left[0, T_{S}\left(t^{\prime}\right)\right]$ or the $\left(T_{S}\left(t^{\circ}\right), T_{P}(1)\right]$ interval, the optimal corporate tax rate is the minimum rate which allows to collect $T^{*}(t)$. This case is less interesting than the previous one because it provides a one to one relationship between welfare and taxation.

Focusing on the first case, we can thus state the following:

Proposition 3 If $\lambda<\lambda^{\circ}(1)$ (or, equivalently, $t^{\circ}<1$ ) and the minimum tax revenue targeted by the Government, $T^{*}(t)$ is in the $\left(T_{S}\left(t^{\prime}\right), T_{S}\left(t^{\circ}\right)\right]$ interval, an increase in the tax rate from $t_{1}^{*} \in\left(t^{\prime}, t^{\circ}\right)$ to $t_{2}^{*} \in\left(t^{\circ}, t^{\prime \prime}\right)$ does not reduce the equilibrium welfare.

According to Proposition 2, a tax rate increase may affect the credit market equilibrium by leading to a pooling equilibrium. If however, the target tax revenue ranges from $T_{S}\left(t^{\prime}\right)$ 
to $T_{S}\left(t^{\circ}\right)$, such an increase does not affect welfare. This is due to the fact that two opposing effects are at work and that their net result is null. In particular, the equilibrium change caused by the corporate tax rate increase yields two offsetting effects. On the one hand, bad firms are now better-off since they are cross-subsidized by good firms and pay a lower interest rate. On the other hand good firms make a loss. ${ }^{19}$ Proposition 3 proves that the net effect is nil and therefore, the equilibrium welfare is unchanged by taxation.

This result has an interesting policy implication, in that it shows that corporate tax increases are not necessarily welfare deteriorating. In other words, if the desired amount of tax revenue ranges from $T_{S}\left(t^{\prime}\right)$ and $T_{S}\left(t^{\circ}\right)$, the Government faces no welfare loss, if it sets a higher tax rate.

\section{Comparative statics}

In order to better understand our findings and their implications, let us next provide a comparative statics analysis. In particular, we are interested in studying how parameter $\lambda$ affects the following two key equilibrium values:

(i) the threshold value $t^{\circ}$ of the corporate tax rate;

(ii) the differential between the interest rates paid by bad and good firms in equilibrium, which we refer to as spread.

We focus on $\lambda$ because an increase (decrease) in the fraction of bad firms can be considered as a proxy for a macroeconomic downturn (recovery).

Given (10), we can show that the pooling equilibrium interest rate $\rho_{P}$ is increasing in $\lambda$. This is due to the fact that the average probability of repayment, $\lambda p_{L}+(1-\lambda) p_{H}$, decreases as the portion of bad firms rises. By contrast, $\lambda$ does not affect the interest rates $\rho_{L}^{*}$ and $\rho_{S}$ paid by bad and good firms, respectively, at the separating equilibrium. We can conclude that good firms, whose optimal choice drives the equilibrium results, are relatively less (more) attracted by the pooling contract $P$ when $\lambda$ increases (decreases). Put differently, an increase (decrease) in $\lambda$ restricts (enlarges) the domain of existence of a pooling equilibrium, i.e.,

$$
\frac{\partial t^{\circ}}{\partial \lambda}=\frac{\left(p_{H}-p_{L}\right)(1+r)}{p_{H}\left(1+r-p_{H}\right)(1-\lambda)^{2}}>0
$$

This result allows us to investigate the joint effect of taxation and the business cycle on the credit market equilibrium and the spread. In particular we focus on two different scenarios.

Scenario 1 Suppose the current corporate tax rate is $t \leq t^{\circ}$. This is always true if $t^{\circ} \geq 1$, or equivalently, $\lambda \geq \lambda^{\circ}(1)$. According to Figure 5, the equilibrium is separating. Since $t^{\circ}$ is increasing in $\lambda$, an economic downturn proxied by higher $\lambda$ does not alter this type of equilibrium. Namely, the spread $\rho_{L}^{*}-\rho_{S}>0$ is not affected by $\lambda$.

In contrast, a recovery proxied by lower $\lambda$ reduces $t^{\circ}$ and may lead to a pooling equilibrium. This occurs if the threshold $t^{\circ}$ decreases below $t$. In that case, the spread $\rho_{L}^{*}-\rho_{S}>0$ becomes equal to zero. If, instead, the decrease in $\lambda$ is small enough, equilibrium is still separating and the spread does not change.

\footnotetext{
${ }^{19}$ We know that $N P V_{H, j}(t)$ is decreasing in $t$ within the relevant interval, either $\left(0, t^{\circ}\right)$ or $\left(t^{\circ}, 1\right)$, and that $N P V_{H, S}\left(t^{\circ}\right)=N P V_{H, P}\left(t^{\circ}\right)$. Since $t_{1}^{*}<t^{\circ}<t_{2}^{*}$, the inequality $N P V_{H, S}\left(t_{1}^{*}\right)>N P V_{H, P}\left(t_{2}^{*}\right)$ holds.
} 
Scenario 2 Suppose the current tax rate is $t>t^{\circ}$ and therefore, the equilibrium is pooling. ${ }^{20}$ Given this starting point we can say that an economic downturn, proxied by a higher $\lambda$, may lead to a separating equilibrium. This occurs if the threshold $t^{\circ}$ increases above $t$. In that case, the spread increases from 0 to $\rho_{L}^{*}-\rho_{S}>0$. If, however, the increase in $\lambda$ is small enough, the equilibrium is still pooling and the spread does not change. ${ }^{21}$

In contrast, a recovery reduces $t^{\circ}$ with the effect that the equilibrium is still pooling: the spread does not change (but the equilibrium interest rate $\rho_{P}$ decreases).

Given these results we can write the following:

Proposition 4 (i) During a downturn, captured in our model by an increase in $\lambda$, the difference, if any, between the interest rate charged to bad firms and that charged to good firms is unaffected when $t \leq t^{\circ}$ or may increase when $t>t^{\circ}$. (ii) During a recovery, captured in our model by an decrease in $\lambda$, the difference, if any, between the interest rate charged to bad firms and that charged to good firms is unaffected when $t>t^{\circ}$ or may decrease when $t \leq t^{\circ}$.

As we have seen, Proposition 1 explains that for any given level of the tax rate $t$ the equilibrium in a credit market characterized by asymmetric information depends on the distribution of bad and good firms. Proposition 2 shows that such an equilibrium can be affected by the Tax Authority: for any given portion $\lambda$ of bad firms in the economy, a relatively low (high) tax rate $t$ is likely to lead to a separating (pooling) equilibrium. By putting together these two results, Proposition 4 enables us to explain the effects of both the business cycle, captured by $\lambda$, and taxation $t$ on the credit market equilibrium.

To this aim, let us recall Figure 1, which shows that the corporate spread between the high-yield (i.e., bad firms in our model) and the investment-grade (good firms) interest rates tends to be high during downturns. According to Proposition 4, such an increase in the spread is more likely to be observed in economies where $t$ is relatively high (i.e., higher than $t^{\circ}$ ). In that case the credit market may shift from a pooling to a separating equilibrium, while the equilibrium is always separating if $t \leq t^{\circ}$.

Conversely, Figure 1 shows that the corporate spread between bad and good firms is generally low during recoveries. Proposition 4 adds that such a decrease in the spread is more likely to be observed in economies where when $t$ is lower than $t^{\circ}$. In that case the credit market may shift from a separating to a pooling equilibrium, while the equilibrium is always pooling if $t>t^{\circ}$.

To conclude, we can state that the effects of the business cycle on the credit market equilibrium may depend not only on asymmetric information and the screening activity by banks, but also on taxation.

\section{Conclusion}

In this article we have analyzed the effects of corporate taxation on credit market equilibrium under asymmetric information. In doing so, we have developed a framework where five pieces of evidence are accounted for: i) the existence of a tax incentive to borrow; ii) the negative relationship between leverage and profitability; iii) the existence of asymmetric information; iv) the screening activity of lenders and v) the business cycle effects on the spread between the high-yield and the investment-grade interest rates on corporate loans.

\footnotetext{
${ }^{20}$ As we know, for the inequality $t>t^{\circ}$ to hold, it is necessary that $t^{\circ}<1$, or equivalently, $\lambda<\lambda^{\circ}(1)$.

${ }^{21}$ The only effect in that case is an increase in the equilibrium pooling interest rate $\rho_{P}$ : see (10).
} 
As we have shown, the characteristics of the equilibrium crucially depend on the distribution of high- and low-profit firms in the economy. If the fraction of bad firms is low enough, lenders offer a pooling contract to firms, which are not credit rationed. If however, the number of bad firms is relatively high, a separating equilibrium is obtained. In this case, bad firms are fully debt-financed, whereas good firms are partially debt-financed. In line with the empirical evidence, we have thus shown that firms with less pressing needs for cash (i.e., good ones) have a lower leverage.

By departing from the relevant literature, we have also shown that corporate taxation affects the credit market equilibrium: the higher (lower) the tax rate, the more likely the pooling (separating) equilibrium is. This is due to the fact that a increase in the corporate tax rate raises the benefit of interest deductibility. As we have proved, there is always a threshold tax rate above (below) which good firms prefer a pooling (separating) contract.

In addition, we have analyzed the welfare effects of corporate taxation. As we have shown, when the target tax revenue is in a given interval, corporate tax rate increases are not necessarily welfare deteriorating. This is due to the fact that the welfare gain for bad firms when moving from a separating to a pooling equilibrium just offsets the welfare loss suffered from good firms. Of course, this result may depend on the fact that aggregate investment is given: we leave a study on endogenously determined investment for future research.

Finally, we have proved that the effects of the business cycle on the credit market equilibrium may work not only through asymmetric information and the screening activity by banks, but also through the level of corporate tax rate. 


\section{A Symmetric information}

To prove Lemma 1, we first stress the fact that firm $i$ 's net present value at time $0\left(N P V_{i}\right)$ depends on the its ability to repay the debt. Of course, firm $i$ 's crucially depend on its leverage. For this reason we study two different scenarios: a no-default and a default one.

Default-free scenario Suppose first the inequality

$$
\left(1+\rho_{i}\right) B_{i} \leq 1+a
$$

holds. In this case, of course, firm $i$ can always repay and thus, no default occurs. According to Claim 1 the lenders' zero-profit condition is:

$$
p_{i}\left(1+\rho_{i}\right) B_{i}+\left(1-p_{i}\right)\left(1+\rho_{i}\right) B_{i}=(1+r) B_{i} .
$$

where $(1+r) B_{i}$ is the lenders' opportunity cost of lending $B_{i}$. Solving (24) for $\rho_{i}$ gives

$$
\rho_{i}=r .
$$

Substituting $\rho_{i}=r$ into (23) and rearranging gives $r B_{i} \leq 1+a-B_{i}$. Next, using the relevant discount factor $\frac{1}{1+r}$ gives:

$$
N P V_{i}= \begin{cases}-E_{i}+\frac{(1-t)\left(R_{i}-r B_{i}\right)+E_{i}}{1+r} & \text { for } r B_{i} \leq a, \\ -E_{i}+p_{i} \frac{(1-t)\left(A-r B_{i}\right)+E_{i}}{1+r}+\left(1-p_{i}\right) \frac{\left(a-r B_{i}\right)+E_{i}}{1+r} & \text { for } a<r B_{i} \leq 1+a-B_{i},\end{cases}
$$

As can be seen, the corporate tax base is given by the difference between gross revenue and the interest expenses $r B_{i} . t$ is the relevant corporate tax rate. Note that firm $i$ makes positive profits with probability 1 when $r B_{i} \leq a$. When however $r B_{i} \in\left(a, 1+a-B_{i}\right]$ firm $i$ repays the debt but the return $a$ is not sufficient to cover the debt $\operatorname{costs} r B_{i}$. In this case, the firm's loss is tax-exempt. Put differently, no subsidy is paid by the Government in case of loss. ${ }^{22}$

Substituting $\rho_{i}=r$ into (23) and using $E_{i}=1-B_{i}$ we can rewrite (26) as follows:

$$
\max _{B_{i}} \begin{cases}-\left(1-B_{i}\right)+\frac{(1-t)\left(R_{i}-r B_{i}\right)+\left(1-B_{i}\right)}{1+r} & \text { for } r B_{i} \leq a \\ -\left(1-B_{i}\right)+p_{i} \frac{(1-t)\left(A-r B_{i}\right)+\left(1-B_{i}\right)}{1+r}+\left(1-p_{i}\right) \frac{\left(a-r B_{i}\right)+\left(1-B_{i}\right)}{1+r} & \text { for } r B_{i} \in\left(a, 1+a-B_{i}\right]\end{cases}
$$

$$
\text { s.t. } B_{i} \leq \frac{1+a}{1+r}
$$

where $\frac{1+a}{1+r} \in[0,1)$ is dealt with in Assumption 1.

The derivative of (27) w.r.t. $B_{i}$ is $\frac{t r}{1+r}>0$ for $r B_{i} \leq a$ and is equal to $\frac{p_{i} t r}{r+1}>0$ for $r B_{i} \in\left(a, 1+a-B_{i}\right]$. This (27) is increasing in $B_{i}$. Of course, this result is due to the deductibility of interest expenses $r B_{i}$. Since no tax relief is ensured to equity issues, firm $i$ maximizes $B_{i}$ and, of course, minimizes $E_{i}$. Thus, the solution to the unique solution to program (27) is

$$
B^{\circ}=\frac{1+a}{1+r}<1
$$

and $E^{\circ}=1-\frac{1+a}{1+r}$.

\footnotetext{
${ }^{22}$ We are focusing on an asymmetric tax system where the relevant tax rate is lower when a firm makes losses. For simplicity, our model states that the tax rate is nil.
} 
Default scenario Suppose now the inequalities

$$
1+a<\left(1+\rho_{i}\right) B_{i} \leq 1+A
$$

hold. In this case, the loan contract $\left\{\rho_{i}, B_{i}\right\}$ is such that the gross cost of borrowing is higher than the firm $i$ 's before-tax gross revenue in the bad case and is weakly lower in the good case. This means that the probability of default is $\left(1-p_{i}\right)$ : in this case the lenders become shareholders. Following Claim 1 the lenders' zero-profit condition is equal to

$$
p_{i}\left(1+\rho_{i}\right) B_{i}+\left(1-p_{i}\right)(1+a)=(1+r) B_{i} .
$$

Solving (30) for $\rho_{i}$ gives

$$
\rho_{0, i}=\frac{r B_{i}-\left(1-p_{i}\right)\left(a+E_{i}\right)}{p_{i} B_{i}} .
$$

It is easy to see that $\rho_{0, i}$ exceeds $r$. Namely, the lenders require a risk premium when a positive probability of default arises. Moreover,

$$
\frac{\partial \rho_{0, i}}{\partial B_{i}}=\frac{\left(1-p_{i}\right)(1+a)}{p B_{i}^{2}}>0 .
$$

This means that the higher the debt level $B_{i} \in\left(\frac{1+a}{1+r}, 1\right]$, the higher the break-even interest rate $\rho_{0, i}$ is. Since the firms are characterized by limited liability and default causes a full loss for previous shareholders, firm i's $N P V$ is equal to:

$$
N P V_{i}=-E_{i}+p_{i} \frac{(1-t)\left(A-\rho_{0, i} B_{i}\right)+E_{i}}{1+r}+\left(1-p_{i}\right) \times 0
$$

Using $E_{i}=1-B_{i}$, we can thus rewrite (33) as

$$
\begin{gathered}
\max _{B_{i}}\left\{-\left(1-B_{i}\right)+p_{i} \frac{(1-t)\left(A-\rho_{0, i} B_{i}\right)+\left(1-B_{i}\right)}{1+r}\right\} \\
\text { s.t. } \frac{1+a}{1+r}<B_{i} \leq 1,
\end{gathered}
$$

The derivative of (34) with respect to $B_{i}$ is $\frac{t\left(1+r-p_{i}\right)}{1+r}>0$. This implies that firm $i$ is fully debt-financed. Of course we have $E^{*}=0$. Substituting $B^{*}=1$ and $E^{*}=0$ into (31) and solving for the lending interest rate now gives

$$
\rho_{i}^{*}=\frac{r-\left(1-p_{i}\right) a}{p_{i}}
$$

where $\rho_{i}^{*}>r$ (see Assumption 1). Moreover, substituting $B^{*}=1$ and (35) into (34), the firm's $N P V$ under default risk is equal to:

$$
N P V_{i}^{*}=\frac{p_{i}(1-t)\left(A-\frac{r-\left(1-p_{i}\right) a}{p_{i}}\right)}{1+r} .
$$

Let us next check whether firm $i$ 's participation constraint is fulfilled in equilibrium. As pointed out, at time 0, Stage 2 of the model's timing in Section 2, the firms' outside option is the maximum between 0 and an equity-financed project: its $N P V$ is given by (27) with $B_{i}=0$ :

$$
O O_{i}=\max \left\{\begin{array}{ll}
0, \frac{(1-t)\left[p_{i} A+\left(1-p_{i}\right) a\right]-r}{1+r} & \text { for } a \geq 0 \\
\frac{p_{i}(1-t) A+\left(1-p_{i}\right) a-r}{1+r} & \text { for } a<0 .
\end{array}\right\}
$$


Given Assumption 2, $O O_{i}$ is never higher than $N P V_{i}^{*}$.

Finally, the case $\left(1+\rho_{i}\right) B_{i}>1+A$ is ruled out by Assumption 2. Indeed, inequality $\left(1+\rho_{i}\right) B_{i} \leq 1+A$ can be rewritten as

$$
\left(1+\frac{r B_{i}-\left(1-p_{i}\right)\left(a+E_{i}\right)}{p_{i} B_{i}}\right) B \leq 1+A
$$

after substituting (31). Since $E_{i}+B_{i}=1$, the LHS of the above inequality reaches its maximum when $B_{i}=1$ (and $E_{i}=0$ ). Substituting $B_{i}=1$ and $E_{i}=0$ into (37) gives $1+\frac{r-\left(1-p_{i}\right) a}{p_{i}} \leq 1+A$, which is fulfilled under Assumption 2 since $\frac{r-\left(1-p_{L}\right) a}{p_{L}}>\frac{r-\left(1-p_{H}\right) a}{p_{H}}$.

\section{B Asymmetric information}

\section{B.1 Lenders' zero-profit curves}

Curves $O H$ and $O L$ derive from the lenders' zero-profit condition (30) under default:

$$
\left[p_{i}(1+\rho)-(1+r)\right] B+\left(1-p_{i}\right)(1+a)=0 .
$$

Solving (38) for $B$ gives

$$
B=\frac{\left(1-p_{i}\right)(1+a)}{1+r-p_{i}(1+\rho)}
$$

Substituting $p_{H}\left(p_{L}\right)$ into (39) gives $O H(O L)$. The derivative of (39) w.r.t. $\rho$ is

$$
\frac{\partial\left[\frac{\left(1-p_{i}\right)(1+a)}{1+r-p_{i}(1+\rho)}\right]}{\partial \rho}=p_{i} \frac{\left(1-p_{i}\right)(1+a)}{\left[1+r-p_{i}(1+\rho)\right]^{2}},
$$

which is positive due to Assumption 1. This proves that $O H$ and $O L$ are upward-sloping.

The cross derivative of (39) w.r.t. $\rho$ and $p$ is

$$
\frac{\partial^{2}\left[p_{i} \frac{\left(1-p_{i}\right)(1+a)}{\left(1+r-p_{i}(1+\rho)\right)^{2}}\right]}{\partial \rho \partial p}=(1+a) \frac{1+r-p_{i}(1+2 r-\rho)}{\left[1+r-p_{i}(1+\rho)\right]^{3}} .
$$

To show that the above value is positive we must first stress that the numerator is increasing $\rho$. Its minimum value is equal to $(1+r)\left(1-p_{i}\right)>0$ and is obtained if $\rho=r$ : this means that the numerator is always positive. Let us next focus on the denominator. As can be seen, $\left[1+r-p_{i}(1+\rho)\right]$ is decreasing in $\rho$. Its minimum value, $\left[1+r-p_{i}\left(1+\frac{r-\left(1-p_{i}\right) a}{p_{i}}\right)\right]$,.is obtained when $\rho=\rho_{i}^{*}=\frac{r-\left(1-p_{i}\right) a}{p_{i}}$. Simplifying $\left[1+r-p_{i}\left(1+\frac{r-\left(1-p_{i}\right) a}{p_{i}}\right)\right.$ gives $\left(1-p_{i}\right)(1+a)>0$. This proves that $O H$ is steeper than $O L$.

\section{B.2 Firms' indifference curves}

Firm $i$ 's indifference curve is obtained by equating its $N P V_{i}$ under default to the $N P V$ obtained by firm $i$ when signing any given contract $X=\left\{\rho_{X}, B_{X}, k\right\}$, i.e.,

$$
-(1-B)+p_{i} \frac{(1-t)(A-\rho B)+(1-B)}{1+r}=-\left(1-B_{X}\right)+p_{i} \frac{(1-t)\left(A-\rho_{X} B_{X}\right)+\left(1-B_{X}\right)}{1+r} .
$$

Solving (40) gives

$$
B=\frac{B_{X}\left\{1+r-p_{H}\left[1+(1-t) \rho_{X}\right]\right\}}{1+r-p_{i}[1+\rho(1-t)]}
$$


Let us next calculate the derivative of (41) w.r.t. $\rho$

$$
\frac{\partial\left[\frac{B_{X}\left[1+r-p_{i}\left(1+(1-t) \rho_{X}\right)\right]}{1+r-p_{i}(1+\rho(1-t))}\right]}{\partial \rho}=p_{i}(1-t) B_{X} \frac{1+r-p_{i}\left[1+\rho_{X}(1-t)\right]}{\left\{1+r-p_{i}[1+\rho(1-t)]\right\}^{2}} .
$$

As can be seen, the numerator of (42) is decreasing in $\rho$. Its minimum value, obtained by setting $\rho=\rho_{i}^{*}=\frac{r-\left(1-p_{i}\right) a}{p_{i}}$, is $1-p_{i}+r t+a(1-t)\left(1-p_{i}\right)>0$. Since the denominator is positive, we can thus conclude that $\frac{\partial\left[\frac{B_{X}\left[1+r-p_{i}\left(1+(1-t) \rho_{X}\right)\right]}{1+r-p_{i}(1+\rho(1-t))}\right]}{\partial \rho}>0$.

Let us next calculate the cross derivative of $(41)$ w.r.t. $\rho$ and $p$. We obtain

$$
\frac{\partial^{2}\left[\frac{B_{X}\left[1+r-p_{i}\left(1+(1-t) \rho_{X}\right)\right]}{1+r-p_{i}(1+\rho(1-t))}\right]}{\partial \rho \partial p}=B_{X}(1+r)(1-t) \frac{1+r-p_{i}\left[1+\left(2 \rho_{X}-\rho\right)(1-t)\right]}{\left\{1+r-p_{i}[1+\rho(1-t)]\right\}^{3}} .
$$

Again, (43) is positive. This can be proven by showing that its numerator is decreasing in $\left(2 \rho_{X}-\rho\right)$ and hence, is minimum when $\left(2 \rho_{X}-\rho\right)$ reaches its maximum value, i.e., $\left[2 \frac{r-\left(1-p_{i}\right) a}{p_{i}}-r\right]$. Substituting term $\left[2 \frac{r-\left(1-p_{i}\right) a}{p_{i}}-r\right]$ into (43) gives $2 a\left(1-p_{i}\right)(1-t)+$ $(1-r)\left(1-p_{i}\right)+r t\left(2-p_{i}\right)>0$. This entails that good firms' indifference curves are steeper than bad firms' ones.

\section{B.3 Separating equilibrium}

We show that both good and bad firms' participation constraints are not binding in the separating equilibrium $(L, S)$. Let us first consider bad firms. They sign their firstbest agreement $\left(\rho_{L}^{*}, 1\right)$. Hence, their participation constraint is not binding as shown in Appendix A. Let us next turn to good firms. Their payoff in separating equilibrium is $N P V_{H, S}$ (derived in (7)). Hence, their participation constraint is not binding if and only if

$$
N P V_{H, S} \geq O O_{H}=\max \left\{\begin{array}{ll}
\frac{\frac{(1-t)\left[p_{H} A+\left(1-p_{H}\right) a\right]-r}{1+r}}{\frac{p_{H}(1-t) A+\left(1-p_{H}\right) a-r}{1+r}} & \text { for } a \geq 0, \\
\text { for } a<0
\end{array}\right\} .
$$

Given this result it worth noting that $N P V_{H, S} \geq \frac{(1-t)\left[p_{H} A+\left(1-p_{H}\right) a\right]-r}{1+r}$ for $a \geq 0$. This implies that $N P V_{H, S} \geq \frac{p_{H}(1-t) A+\left(1-p_{H}\right) a-r}{1+r}$ for $a<0$. Moreover, the $N P V_{H, S} \geq \frac{(1-t) R_{H}-r}{1+r}$ inequality holds. This means that, using (1), (5) and (6), the inequality

$$
t \frac{\left(p_{H}-p_{L}\right)\left[a\left(1-p_{H}\right)+r p_{H}+a r(1-t)\right]+\left(1-p_{H}\right)\left[a t p_{L}+t p_{H}(r-a)\right]+r^{2} t p_{H}}{(1+r)\left[(1+r)\left(p_{H}-p_{L}\right)+t p_{L}\left(1-p_{H}\right)+r t p_{L}\right]} \geq 0
$$

holds. Finally we need to show that $N P V_{H, S} \geq 0$. To do so, we first stress the fact that $N P V_{H, S}$ is continuous in $t \in(0,1]$. Secondly, we have $N P V_{H, S}=0 \Leftrightarrow t_{1}=$ $-\frac{\left(p_{H}-p_{L}\right)(1+r)\left(R_{H}-r\right)}{p_{H}\left(1+r-p_{H}\right)\left(R_{L}-r\right)}<0$ and $t_{2}=1$. Thirdly, $N P V_{H, S}$ is positive when $t=0$ (in this case it is equal to $\frac{R_{H}-r}{1+r}$ ). We can therefore say that the inequality $N P V_{H, S} \geq 0$ is proven for $t \in(0,1]$.

\section{B.4 Pooling contract}

Under pooling contracts, both types of firms are attracted. Thus, the equation of the pooling zero-profit curve $O P$ is given by the following average zero-profit condition:

$$
\begin{gathered}
\lambda\left\{\left[p_{L}(1+\rho)-(1+r)\right] B+\left(1-p_{L}\right)(1+a)\right\}+ \\
(1-\lambda)\left\{\left[p_{H}(1+\rho)-(1+r)\right] B+\left(1-p_{H}\right)(1+a)\right\}=0 .
\end{gathered}
$$


Solving by $B$ gives

$$
B=\frac{\lambda\left(1-p_{L}\right)(1+a)+(1-\lambda)\left(1-p_{H}\right)(1+a)}{\lambda\left[(1+r)-p_{L}(1+\rho)\right]+(1-\lambda)\left[(1+r)-p_{H}(1+\rho)\right]} .
$$

Substituting $B=1$ and solving by $\lambda$ gives (9).

\section{B.5 Cutoff value $\lambda^{\circ}$}

To calculate $\lambda^{\circ}$ we substitute $\rho_{S}$ and $B_{S}$ into (41) with $i=H$ : this gives the indifference curve $H^{\prime} H^{\prime \prime}$ which passes through $S$. In symbols we have

$$
B=\frac{B_{S}\left\{1+r-p_{H}\left[1+(1-t) \rho_{S}\right]\right\}}{1+r-p_{H}[1+\rho(1-t)]} .
$$

Solving for $\rho$ gives

$$
1=\frac{B_{S}\left\{1+r-p_{H}\left[1+(1-t) \rho_{S}\right]\right\}}{1+r-p_{H}[1+\rho(1-t)]} .
$$

This result gives the value of $\rho_{H^{\prime \prime}}$ in contract $H^{\prime \prime}=\left(\rho_{H^{\prime \prime}}, 1\right)$ (see Figure 3 ):

$$
\rho_{H^{\prime \prime}}=\frac{1+r-p_{H}-B_{S}\left[1+r-p_{H}\left(1+(1-t) \rho_{S}\right)\right]}{p_{H}(1-t)} .
$$

Let us next equate $\rho_{H^{\prime \prime}}$ to $\rho_{P}$, i.e., (9). Solving this equality for $\lambda$ gives

$$
\lambda=\frac{p_{H}\left\{1+r t-p_{H}+a\left(1-p_{H}\right)(1-t)-B_{S}\left[\left(1+r-p_{H}\right)-\rho_{S} p_{H}(1-t)\right]\right\}}{\left(p_{H}-p_{L}\right)\left\{1+r-p_{H}-a p_{H}(1-t)-B_{S}\left[\left(1+r-p_{H}\right)-\rho_{S} p_{H}(1-t)\right]\right\}} .
$$

Substituting $\rho_{S}$ (derived in (5)) and $B_{S}$ (derived in (6)) into (45) and rearranging gives the threshold value $\lambda^{\circ}$.

\section{B.6 Candidate pooling equilibrium contract}

To analyze this candidate equilibrium we use Figure A1. Suppose that all lenders offer a pooling contract $Q=\left(\rho_{Q} ; B_{Q}\right)$ lying on the pooled zero-profit line $O P$, with $\rho_{Q}<\rho_{P}$ and $B_{Q}<1$. Curves $H^{\prime} H^{\prime \prime}$ and $L^{\prime} L^{\prime \prime}$ are $H$ - and $L$ - firms' indifference curve, respectively, through contract $Q$. Notice that contract $Q$ cannot be an equilibrium, since at least one lender is able to offer another pooling contract with commitment, $Q^{\prime}=\left(\rho_{Q^{\prime}} ; B_{Q^{\prime}}\right)$ and $k=1$, placed in area $Q P H^{\prime \prime}$, with $\rho_{Q}<\rho_{Q^{\prime}}$ and $B_{Q}<B_{Q^{\prime}} \leq 1$. Contract $Q^{\prime}$ would be preferred by both types of firms and would ensure positive profits to the lender. This reasoning holds for any contract whose debt size is less than one. As a consequence, $P=\left(\rho_{P} ; 1\right)$ is the only candidate pooling equilibrium contract. 


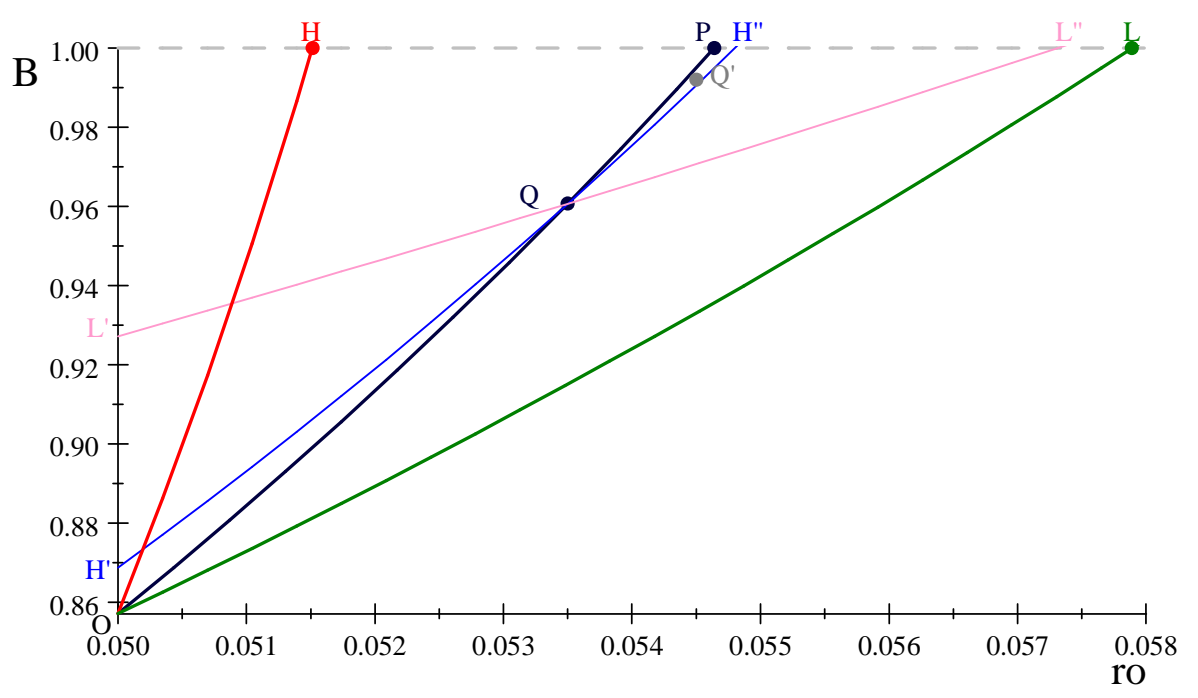

Figure A1. No PoOLing Equilibrium With COMmitment

\section{B.7 Rationing contracts}

Let us study the existence of rationing equilibrium contract(s), where one type of firms signs a contract, while the other type signs no contract.

(i) Assume that the rationing equilibrium contract, if any, is accepted only by good firms. Given Bertrand competition, therefore, it must be contract $H=\left\{\rho_{H}^{*} ; 1\right\}$. As pointed out however, contract $H$ would also be chosen by bad firms. This implies that $H$ cannot be a rationing equilibrium.

(ii) Assume now that the rationing equilibrium contract is accepted only by bad firms. Again, given Bertrand competition, it must be contract $L=\left\{\rho_{L}^{*} ; 1\right\}$. If however all lenders offer $L$, at least one lender can profitably deviate. If $\lambda<\lambda^{\circ}$ she can offer the pooling contract with commitment, $D=\left\{\rho_{D} ; B_{D}\right\}$ and $k=1$, thereby earning positive profit (see Figure 3). If $\lambda \geq \lambda^{\circ}$, she can propose both $L$ and a second contract $S^{\prime}=\left\{\rho_{S^{\prime}} ; B_{S^{\prime}}\right\}$, with $k=1, \rho_{S^{\prime}} \geq \rho_{S}$ and $B_{S^{\prime}} \leq B_{S}$ (see Figure 2). This contract is signed only by good firms and yields positive profit. We can therefore conclude that, irrespective of the degree of commitment, no rationing equilibrium contract exists.

\section{B.8 Candidate SPNE in $B \in\left[0, \frac{1+a}{1+r}\right]$}

As shown in Appendix A, when $B \in\left[0, \frac{1+a}{1+r}\right]$, both types of firms always repay and the only SPNE is a pooling equilibrium, where each firm $i$ signs contract $\left\{r, \frac{1+a}{1+r}\right\}$ (see (25) and (28)). This contract is denoted by $O$ in Figures 2 and 4 . We state that contract $O$ is dominated both by separating contracts $L$ and $S$ and by the pooling one $P$. Indeed, it is easy to check that, in Figure 2, the indifference curves of bad and good firms passing through $L$ and $S$, (curves $L^{\prime} L$ and $H^{\prime} H^{\prime \prime}$ ) lie north-west of the corresponding curves through $O$. The same is true for the indifference curves $L^{\prime} P$ and $H^{\prime} P$ which pass through $P$, in Figure 4 . 


\section{Welfare analysis}

\section{C.1 Equilibrium welfare as a function of $t$}

Let us first prove that the pooling equilibrium welfare $W_{P}(t)$ is decreasing in $t$. Indeed, differentiating $W_{P}(t)$ w.r.t. $t$ gives

$$
\frac{\partial\left\{W_{P}(t)=\left[\lambda p_{L}+(1-\lambda) p_{H}\right] \frac{(1-t)\left(A-\rho_{P}\right)}{1+r}\right\}}{\partial t}=-\frac{\left[\lambda p_{L}+(1-\lambda) p_{H}\right]\left(A-\rho_{P}\right)}{1+r}<0 .
$$

The analysis of the separating equilibrium welfare $W_{S}(t)$ is more complex. For this reason, we use the numerical example of Figures 2,3 and $4 .{ }^{23}$ We thus obtain:

$W_{S}(t)=0.5 \frac{.95(1-t)\left(.5-\frac{.05+(1-.95) .1}{.95}\right)}{1+.05}+0.5 \frac{2(99 t+74)}{25} \frac{1-t}{19 t+14}=\frac{-194 t^{2}+50 t+144}{475 t+350}$,

with

$$
\frac{\partial \frac{-194 t^{2}+50 t+144}{475 t+350}}{\partial t}=-\frac{2}{25} \frac{2716 t+1843 t^{2}+1018}{(19 t+14)^{2}}<0 .
$$

\section{C.2 Particular values of the equilibrium welfare}

Let us first prove that $W_{S}(0)>W_{P}\left(t^{\circ}\right)$. Substituting $t=0$ into (16) gives

$$
W_{S}(0)=\lambda \frac{p_{L} A+\left(1-p_{L}\right) a-r}{1+r}+(1-\lambda) \frac{p_{H} A+\left(1-p_{H}\right) a-r}{1+r} .
$$

Substituting $t^{\circ}$ into (14) gives

$$
W_{P}\left(t^{\circ}\right)=\left[\lambda p_{L}+(1-\lambda) p_{H}\right] \frac{\left(1-\frac{\lambda}{1-\lambda} \frac{p_{H}-p_{L}}{p_{H}} \frac{1+r}{1+r-p_{H}}\right)\left\{A-\frac{r-a\left[\lambda\left(1-p_{L}\right)+(1-\lambda)\left(1-p_{H}\right)\right]}{\lambda p_{L}+(1-\lambda) p_{H}}\right\}}{1+r} .
$$

Rearranging $\left[W_{S}(0)-W_{P}\left(t^{\circ}\right)\right]$ gives

$$
\lambda\left(p_{H}-p_{L}\right) \frac{\lambda\left[p_{L} A+\left(1-p_{L}\right) a\right]+(1-\lambda)\left[p_{H} A+\left(1-p_{H}\right) a\right]-r}{p_{H}(1-\lambda)\left(1+r-p_{H}\right)},
$$

which is positive due to Assumption 2.

We finally prove that $W_{S}\left(t^{\circ}\right)>W_{P}(1)=0$. Notice that $W_{S}(t)$ decreases in $t$ and that $W_{S}\left(t^{\circ}\right)$ is higher than $W_{S}(1)$ for $t^{\circ}<1$ (i.e., for $\lambda<\lambda^{\circ}(1)$ ). Moreover we have

$$
W_{S}(1)=(1-\lambda) \frac{-\left(1+r-p_{H}\right)\left(1-B_{S}\right)}{1+r} .
$$

Since $B_{S}=1$ for $t=1$, we can therefore conclude that $W_{S}\left(t^{\circ}\right)>W_{S}(1)=W_{P}(1)=0$.

\footnotetext{
${ }^{23}$ Remember that, in these Figures, the parameter values are: $p_{L}=.95 ; p_{H}=.99 ; r=.05 ; A=.5$; $a=-.1 ; t=.3 ; \lambda=0.5$.
} 


\section{References}

[1] Akerlof, G. A., 1970, The Market for 'Lemons': Quality Uncertainty and the Market Mechanism, Quarterly Journal of Economics, 84, pp. 488-500.

[2] Berger, A. N., and Black, L. K., 2011, Bank Size, Lending Technologies, and Small Business Finance, Journal of Banking and Finance, 35, pp. 724-735.

[3] Boadway, R., and Keen, M., 2006, Financing and Taxing New Firms under Asymmetric Information, FinanzArchiv/Public Finance Analysis, 62, pp. 471-502.

[4] Cooper, I.A., and Nyborg, K.G., 2008, Tax-Adjusted Discount Rates with Investor Taxes and Risky Debt, Financial Management Association International, 37, pp. 365-379.

[5] de Meza, D., and Webb, D.C., 1987, Too Much Investment: A Problem of Asymmetric Information, Quarterly Journal of Economics, 102, pp. 281-292.

[6] Fuest, C., and P. Tillessen, 2005, Why do governments use closed ended subsidies to support entrepreneurial investment?, Economics Letters, 89, pp. 24-30.

[7] Gordon, R.H., 2010, Taxation and Corporate Use of Debt: Implications for Tax Policy, National Tax Journal, 63, pp. 151-174.

[8] Graham, J.R., 1999, Do Personal Taxes Affect Corporate Financing Decisions?, Journal of Public Economics, 73, pp. 147-185.

[9] Graham, J.R., 2000, How Big are the Tax Benefits of Debt?, Journal of Finance, 55, pp. 1901-1941.

[10] Graham, J.R., 2003, Taxes and Corporate Finance: A Review, Review of Financial Studies, 16, pp. 1075-1129.

[11] Graham, J.R., Hazarika S., and Narasimhan, K., 2011, Financial Distress in the Great Depression, Financial Management, pp. 821 - 844.

[12] Graham, J.R., Lemmon M.L., and Schallheim J.S., 1998, Debt, Leases, Taxes, and the Endogeneity of Corporate Tax Status, Journal of Finance, 53, pp. 131-162.

[13] Hanlon, M., and Heitzman, S., 2010, A Review of Tax Research, Journal of Accounting and Economics, 50, pp. 127-178.

[14] International Monetary Fund, 2013, Global Financial Stability Report, October, $I M F$, Washington, DC

[15] Kaplow, L., 2008, The Theory of Taxation and Public Economics, Princeton University Press, New Jersey.

[16] Koufopoulos, K., 2011, Endogenous Commitment and Nash Equilibria in Competitive Markets with Adverse Selection, working paper.

[17] Kraus, A., and Litzenberger, R.H., 1973, A State-Preference Model of Optimal Financial Leverage, Journal of Finance, 28, pp. 911-922.

[18] Leland, H.E., 1994, Corporate Debt Value, Bond Covenants, and Optimal Capital Structure, Journal of Finance, 49, pp. 1213-1252.

[19] Minelli, E., and Modica, S., 2009, Credit Market Failures and Policy, Journal of Public Economic Theory, 11, pp. 363-382.

[20] Miniaci, R., Panteghini, P.M., and Parisi, M.L., 2014, Debt shifting in Europe, International Tax and Public Finance, forthcoming. 
[21] Myers, S.C., and Majluf, N.S., 1984, Corporate Financing and Investment Decisions When Firms Have Information that Investors Do Not Have, Journal of Financial Economics, 13, pp. 187-221.

[22] Myers, S.C., 1993, Still Searching for the Optimal Capital Structure, Journal of Applied Corporate Finance, 6, pp. 4-14.

[23] Myers, S.C., McConnell, J., Peterson, A., Soter, D., and Stern, J., 1998, Vanderbilt University Roundtable on the Capital Structure Puzzle, Journal of Applied Corporate Finance, 11, pp. 8-24.

[24] Simon, J., 2012, Optimal Debt Bias in Corporate Income Taxation, EUI Working Paper Max Weber Programme 2012/13.

[25] Stiglitz, J.E., and Weiss, A., 1981, Credit Rationing in Markets with Imperfect Information, American Economic Review, 71, pp. 393-410.

[26] Strebulaev, I. A., 2007, Do Tests of Capital Structure Theory Mean What They Say?, Journal of Finance, 62, pp. 1747-1787.

[27] Uchida, H., 2011, What Do Banks Evaluate When They Screen Borrowers? Soft Information, Hard Information and Collateral, Journal of Financial Services Research, 40, pp. 29-48.

[28] van Binsbergen, J.H., Graham, J.R., and Yang, J., 2010, The Cost of Debt, Journal of Finance, 65, pp. 2089-2136.

[29] Wilson, C., 1977, A Model of Insurance Markets with Incomplete Information, Journal of Economic Theory, 16, pp. 167-207. 